\title{
Review, Challenges and Future Developments of Electric Taxiing Systems
}

\author{
Milos Lukic, Student Member, IEEE, Paolo Giangrande, Member, IEEE, Ahmed Hebala, Stefano Nuzzo, Member, \\ IEEE and Michael Galea, Senior Member, IEEE
}

\begin{abstract}
The ever-increasing demand for passenger air traffic results in larger airline fleets every year. The aircraft market forecast reveals an unprecedented growth for the coming decades, leading to serious environmental and economic concerns among airlines and regulatory bodies. Different approaches, for both airborne and ground operations, have been proposed to reduce and control emissions without compromising profit margin. For on-ground activities, the electric taxiing (ET) methodology is one of the suggested solutions for reducing the emissions and the acoustic noise in the airport, and for lowering the fuel consumption and operating costs. This paper thus aims to review and collate the more important literature related to electric taxiing systems (ETSs), in order to draw an inclusive picture regarding the current state of the art of a moving and growing sector that just started its first steps towards an ambitious target. After introducing the general concept of ET, elaborations on the benefits and challenges of available technologies are done with a detailed comparison of the different systems. Finally, recommendations for future research and outlook on ET are presented.
\end{abstract}

Index Terms-Electric taxiing, More Electric Aircraft, Fuel Consumption, Emission Reduction, Local Energy Storage System.

\section{INTRODUCTION}

$\mathrm{T}$ HE aviation industry is one of the fastest-growing contributors of greenhouse gas emissions ( $\mathrm{CO} 2, \mathrm{CO})$, unburned hydrocarbons (HC) and mono-nitrogen oxides (NOx). In 2017, direct emissions from the aviation sector amounted to approximately $2.2 \%$ of the total global $\mathrm{CO}_{2}$ emissions [1]. In the EU, aviation accounts for $3 \%$ of total greenhouse emissions [2], while this share is $6 \%$ in the UK [3]. Partly due to liberalization policies and to the successful emergence of budget airlines, air traffic will inevitably continue to increase in the following years [4]. Airbus, a major European aerospace corporation, has estimated that the number of passenger aircraft will be more than doubled by 2037, compared to the 21,450 aircraft that were operational at the beginning of 2018 [5]. Consequently, the fuel consumption and emissions generated by the aerospace industry will dramatically rise [6]. Thus, it is not surprising that ecological concerns are

This work is funded by the INNOVATIVE doctoral programme. The INNOVATIVE programme is partially funded by the Marie Curie Initial Training Networks (ITN) action (project number 665468) and partially by the Institute for Aerospace Technology (IAT) at the University of Nottingham.

All authors are with the Power Electronics, Machines and Control (PEMC) group within the University of Nottingham, United Kingdom (email: Milos.Lukic@nottingham.ac.uk, Ahmed.Hebala@nottingham.ac.uk, Paolo.Giangrande@Nottingham.ac.uk, Stefano.Nuzzo@nottingham/ac/uk, one of the key drivers calling for more efficient and sustainable operation of the aerospace industry. Many regulatory bodies agreed to limit the environmental impact of this growth by imposing common targets, such as 1) reduction of $\mathrm{CO}_{2}$ emissions for $75 \%$ per passenger kilometre, 2) $90 \%$ decreasing of $\mathrm{NO}_{\mathrm{x}}$ emissions, and 3) minimization of noise, as presented in Flight Path 2050 strategy. All the aimed reductions are referred to the levels recorded in 2000 [7].

Aviation fuel typically comprises $25 \%$ or more of airline costs and, it accounts for over $97 \%$ of airline $\mathrm{CO}_{2}$ emissions [8]. Considering that the price of jet fuel is steadily going up, after the temporary 2015's drop [9], aircraft manufacturers in accordance with airlines are focusing development efforts in search of ever more fuel-efficient and eco-friendly aircraft, to reduce the economic impact and most importantly to comply with the environmental goals of the 2050 strategy. The more electric aircraft (MEA) initiative falls within this tendency [10].

It is perceived that the MEA and, in the future, all-electric aircraft (AEA) technologies can decrease fuel consumption by $9 \%$ [11]. Besides these benefits, it is also anticipated that MEA and AEA concepts will lead to an overall average weight cut by $10 \%$. The best example of the MEA initiative is probably the Boeing 787 Dreamliner. Indeed, its electrical loads require almost $1000 \mathrm{kVA}$, a significant step when compared to the 300 $\mathrm{kVA}$ of a more conventional Airbus A320 [12]. Taking into consideration the different number of maximum passengers onboard, a $72 \%$ increase in terms of power-per-passenger is registered (2.78 kVA-per-passenger for Boeing 787 and 1.61 kVA-per-passenger for Airbus A320) [13].

Historically, any effort related to fuel efficiency improvements has mainly concentrated on the airborne phase of the flight, but nowadays the on-ground phases of the flight mission - especially the taxiing part - are also being considered as important areas of improvement. In Fig. 1, the typical onground procedures of a commercial aircraft are illustrated. These include landing and take-off, along with taxi-in, pushback, and taxi-out activities. According to the International Civil Aerospace Organisation (ICAO), taxiing is defined as the flight phase in which the movement of an aircraft under its own

Stefano Nuzzo is also with the Department of Engineering Enzo Ferrari within Università degli Studi di Modena e Reggio Emilia, Italy (email: Stefano.Nuzzo@unimore.it)

Michael Galea is also with the Key Laboratory of More Electric Aircraft Technology of Zhejiang Province, University of Nottingham Ningbo China (email: Michael.Galea@nottingham.edu.cn) 


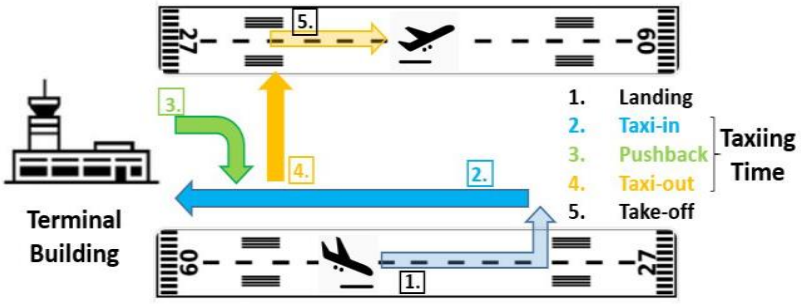

Fig. 1. On-ground phases of the flight.

power occurs on the surface of an aerodrome, excluding takeoff and landing [14], [15]. Between taxi-in and taxi-out there is pushback, i.e., a phase during which the aircraft is manoeuvred in the gate or parking area. Once the plane is cleared for the next departure, it is pushed back by assisted tow vehicle, because the adoption of jet engines for backwards drive imposes safety issues, such as the high risk of foreign object damage (FOD). Hence, since aircraft movement does not take place under its own power, the pushback is not considered as part of taxiing by ICAO. However, some regulatory bodies, such as EUROCONTROL, incorporate the pushback time within the taxiing time [16]. Seeing that the pushback and the taxiing are tightly related and sequential procedures, in this paper, pushback time will be considered as part of taxiing time to avoid ambiguity.

Conventionally, the aircraft main engines are used during the taxiing phase, set with an idle thrust of 7\% [17]. This means that the engines are operating in a non-optimum thrust range because they are designed to be fuel-efficient at the airborne phase of the flight only. Furthermore, at highly congested airports, the taxiing-out time can exceed 30 minutes [18], leading to considerable fuel burn and high emission rates. In fact, more than $56 \%$ of the total $\mathrm{NO}_{\mathrm{x}}$ generation in 2002 at Heathrow airport was due to taxiing [19], whereas this value is estimated around 22\% at Zurich airport [20]. The cost of fuel used for taxiing is expected to reach over $\$ 7$ billion by 2020 , emitting over 23 million $\mathrm{t}$ of $\mathrm{CO}_{2}$ and amounting to over $\$ 440$ million in $\mathrm{CO}_{2}$ tax emissions penalties [21], [22].

For pushback, additional tractors and tugs are required to move the aircraft backwards, thus significantly reducing its autonomy. Indeed, pushback operations have been identified as the most significant contributor of slowing down the total ground procedure [23], mainly due to 1) the long waiting time of various security clearances that have to be issued by the ground control, 2) the lack of available tractors and 3) the mechanical reliability of connecting bars and pins. In [23], it is reported that the average time between requesting a pushback and starting to taxi-out is $8 \mathrm{~min}$, while $98 \%$ of pushback activities (on-time performance) are ideally completed in less than 20 minutes. In addition to the already mentioned 2050 requirements, all taxiing procedures are required to be carbonneutral by that date. Several solutions have been proposed as an alternative to the conventional taxiing and, in a broad sense, they can be categorized into operational and technological methods [24], as illustrated in Fig. 2.

The operational measures involve the improvement of operations at the airport level and they have already been relatively successful due to the ease of their implementation. The most prevalent method is the single-engine taxiing, in which only one engine is used for aircraft movement. Other techniques,

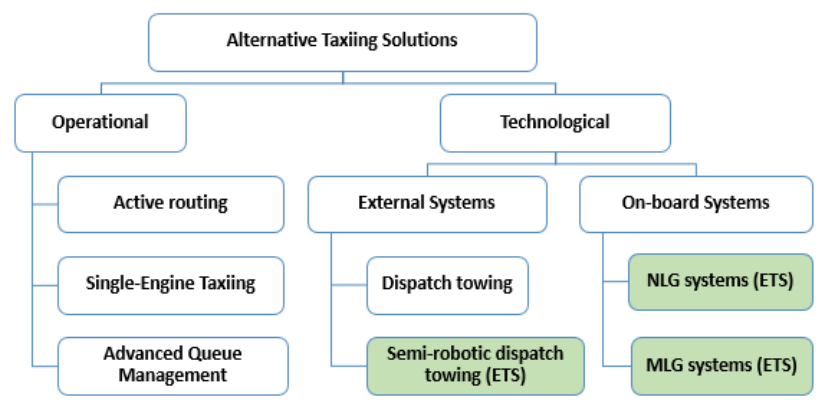

Fig. 2. The proposed categorisation of alternative taxiing solutions.

such as active routing and advanced queue management, are based on the ground traffic optimisation to reduce taxiing times [25], [26]. On the other hand, technological solutions are based on the employment of a particular technology that allows for smarter and greener taxiing. The main difference between these two options is that operational solutions still require the use of engines for the ground movement, while the technological ones are engineless-based approaches. The latter, in turn, can be grouped into 1) on-board and 2) external systems.

Application of external systems relies on a car-like vehicle to perform towing of the aircraft. The so-called dispatch towing method employs the standard towing tractors already used for pushback, which burn diesel, gasoline or natural gas that are all cheaper than aviation fuel. Even though emissions from the onground vehicles are increased in total, this method shows fewer emissions on average compared to conventional aircraft enginebased taxiing [27]. The semi-robotic dispatched towing employs more efficient and environmentally friendly electric (fully or hybrid) trucks for towing purpose. Instead, on-board systems are entirely located in the aircraft and they rely on the concept of an electrical drive system (EDS), which typically consists of an electrical motor, a power converter, a control system, and an electric energy source [28]. An advantage of on-board systems is the improved aircraft's autonomy, as it does not depend on ground crew or equipment, as well as the capability of implementing regenerative braking [29]. An electric traction motor (TM) is installed in the wheel of either the nose landing gear (NLG) or the main landing gear (MLG).

All on-board and external semi-robotic towing solutions embrace the MEA initiative, as they use electric energy at one point of the energy conversion stage. Therefore, these engineless options can be named as electric taxiing systems (ETSs). A generic system architecture for both on-board and external systems is shown in Fig. 3, where APU stands for the auxiliary power unit.

Although the idea of the powered wheel has already been investigated, only recently more effort has been invested towards commercialisation of those systems [30]. In 2005, the first proof of an ET concept was positively demonstrated by the company WheelTug. It was an on-board system installed at the NLG of a Boeing 767 loaded with $94 \%$ of its maximum take-off weight (MTOW) [31], [32]. Since then, numerous studies have been conducted highlighting both economic and environmental benefits related to the ETSs utilization [26], [33]. Therefore, many companies had naturally recognized this market potential announcing the development of various ETSs. Yet, a comprehensive analysis and comparative studies of the proposed 


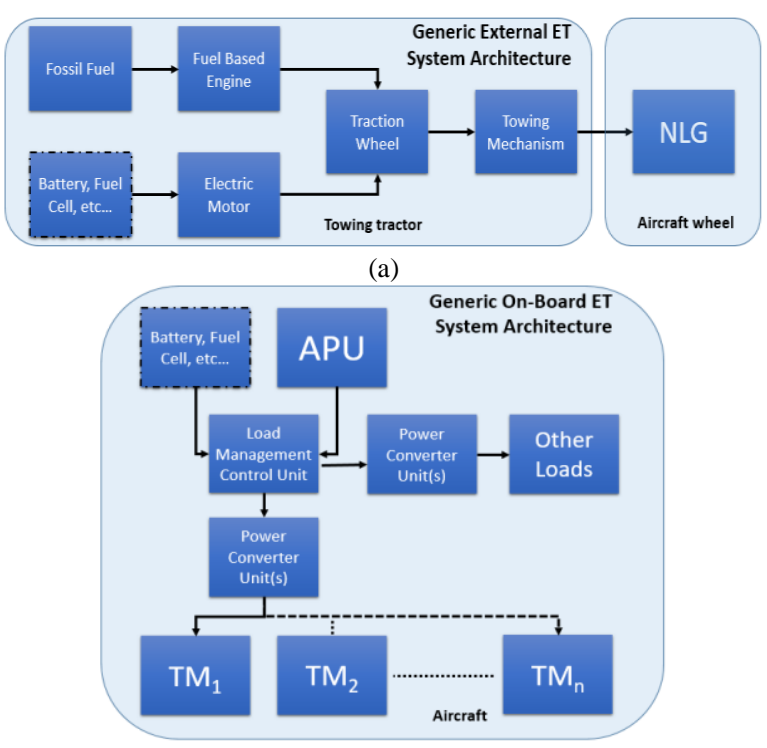

(b)

Fig. 3. A generic system architecture for both (a) external and (b) onboard ETSs.

systems are still lacking in the literature. Hence, the main goal of this paper is to provide a broad review of the proposed ETSs, compare them, address the benefits and challenges in their implementation and outline the directions of future research.

In terms of paper content, the main features and operation principles of the available ETSs are described in section II, highlighting the advantages and drawbacks of each of them. Section III thoroughly discusses the studied systems in terms of benefits, savings, configuration, etc. Both technological and operational challenges are presented in Section IV, along with recommendations for future research. Finally, the conclusions of this 'journey' through the ETSs are drawn in Section V.

\section{REVIEW OF ELECTRIC TAXIING SYSTEMS}

In this section, a review of the recent developments of ETSs is presented. Only the systems that can tow at least a commercial, regional narrow-body aircraft up to MTOW equivalent to an Airbus A320 or Boeing 737 are considered. In addition, all of the described ETSs have demonstrated technological readiness level (TRL) 5 or higher.

\section{A. External ETSs}

Over the last years, some fully electric and hybrid electric systems have emerged as an alternative to the diesel and gasoline-based towing tractors. In this section, a number of these systems will be introduced along with a sub-category of external ETSs, called electric pushback (EP) systems.

The primary advantage of using external ETSs, compared to other alternative solutions, is that these are non-invasive to the aircraft design. This feature facilitates the certification process and consequently encourages the approval and adoption by airline operators. It also means that no extra weight is added onboard the aircraft. On the other hand, apart from greatly diminishing the aircraft autonomy, a perceived main disadvantage of these systems is that they can increase congestion between the gates and the runways, due to the increased number of towing trucks in operation. Hence, modifications to the airport infrastructure ought to be made, such as new roads for tractor movement after the aircraft's take-off. Also, using external ETSs during taxi-in faces logistic efforts associated with connecting the tractor to the arriving airplane [34]; thus, potentially lengthening the taxiing-in time. Despite the drawbacks, these systems proved to be popular among airlines with some of them currently being operational worldwide, as detailed in the upcoming subsections.

\section{1) EP Systems}

EP systems are designed to replace conventional fuel towing tugs with electrical ones. A general observation for the EP systems is that they operate at very low speeds, i.e., 2-6 knots $(3.7-11.1 \mathrm{~km} / \mathrm{h})$, and therefore they are only acceptable for the pushback operation itself. Some of the major providers of this technology are Mototok [35], Charlatte-America [36], EagleTugs [37], and Lektro [38]. A comparison of these manufacturers is summarized in Table I. While each company has a number of models and tugs, the comparative exercise considers only towbarless models with the highest towing capability (i.e., able of towing at least regional jet). For the sake of completeness, examples of these tugs are shown in Figs. 4(a) and (b). Similarly to ETSs, EP ones can also actively reduce the emissions and the fuel consumption compared to conventional diesel tugs. So far, all of these models use lead acid batteries with operating voltages varying from 40 to $80 \mathrm{~V}$. Being electrically powered, no emissions and comparatively low noise

Table I. EP Systems Comparison.

\begin{tabular}{|c|c|c|c|c|}
\hline Criteria & Mototok & Charlatte & LEKTRO & Eagle \\
\hline Tractor Model & Spacer 8600 & CPB35E & AP89 & EJP-12 \\
\hline Towing capacity $[t]$ & 86 & 116 & 127 & 45 \\
\hline Traction power $[\mathrm{kW}]$ & 2 traction motors & $\begin{array}{c}2 * 26 \\
\text { AC motors }\end{array}$ & $\begin{array}{c}2 * 45.5 \\
\text { DC motors }\end{array}$ & $\begin{array}{c}2 * 17 \\
\text { AC motor }\end{array}$ \\
\hline Battery voltage [V] & 48 & 80 & 40 & 72 \\
\hline Battery capacity [Ah] & 300 & 500 & 595 & 440 \\
\hline $\mathbf{N}^{0}$ batteries & 2 & 2 & 2 & 1 \\
\hline Towing speed [km/h] & 3.6 to 10 & 11.3 (unloaded) & 6.44 & 4.8 \\
\hline Driving Method & Remotely & $\begin{array}{c}\text { Driver required + extra } \\
\text { operator }\end{array}$ & $\begin{array}{c}\text { Driver required + extra } \\
\text { operator }\end{array}$ & $\begin{array}{c}\text { Driver required + extra } \\
\text { operator }\end{array}$ \\
\hline $\begin{array}{c}\text { Dimensions } \\
(\mathbf{L}-\mathbf{W}-\mathbf{H})[\mathrm{m}]\end{array}$ & $4-4-0.88$ & $5-2.3-1.86$ & $6.2-2.5-0.99$ & $5.6-1.9-0.99$ \\
\hline
\end{tabular}




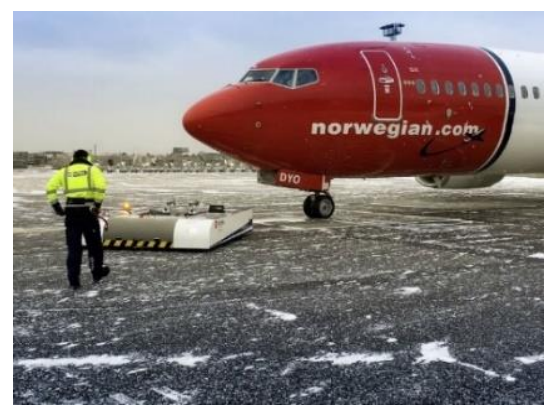

(a)

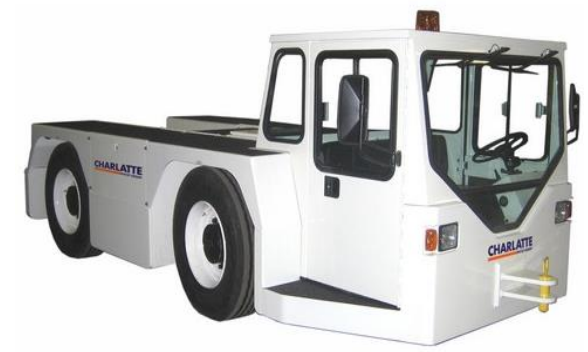

(b)

Fig. 4. Electric tug (a) remotely controlled - Mototok engaging to Boeing 737 [35] and (b) driver operated - Charlatte CPB35E [36].

during the pushback procedures are exhibited. Furthermore, these systems are smaller compared to conventional tractors, thus allowing more accessible storage and more flexible manoeuvring in the airport hangars. In addition to these benefits, Mototok - operational now worldwide - requires no driver, no driving licence, and hence, it offers lower operating, personnel training, and investment costs, as well as, more straightforward certifications process. Finally, since the operator is not located inside the truck, as can be seen in Fig. 4(a), a broader and better view angle is granted, allowing safer pushback operations.

\section{2) TaxiBot External ETS}

TaxiBot is an external ETS developed by Israeli Aerospace Industries (IAI), as illustrated in Fig. 5(a). In particular, it is a semi-autonomous hybrid electric tractor designed to tow the aircraft during all the on-ground procedures (i.e., pushback, taxi-out, and taxi-in). Due to safety and redundancy reasons, its powertrain consists of two diesel engines each driving an electric generator, which cooperate in supplying eight electric motors installed within four wheels.

The maximum power to the road of the whole TaxiBot vehicle is $500 \mathrm{~kW}$ with maximum achievable torque of $45 \mathrm{kNm}$ and with these specifications, the tractor can reach a speed of 23 knots $(42.6 \mathrm{~km} / \mathrm{h})$ towing a Boeing 737 at MTOW [39]. It is important to emphasize that the Taxibot is steered by the pilot through a tiller as in normal taxiing, which is a significant feature as it partially reinstates aircraft autonomy and therefore improves safety and accountability [40]. Such feature is obtained through a unique towbarless NLG interface clamping mechanism mounted on a rotating turret platform, as depicted in Fig. 5(b) [41].Sensors installed onto the platform detect the steering angle of the NLG and steer all wheels of the tow tractor [42]. The braking phase is accomplished, as in conventional taxiing, using brake pedals that control the braking system in the MLG [40]. Although the aircraft pilot controls most of the taxiing processes, the tractor driver is still required for

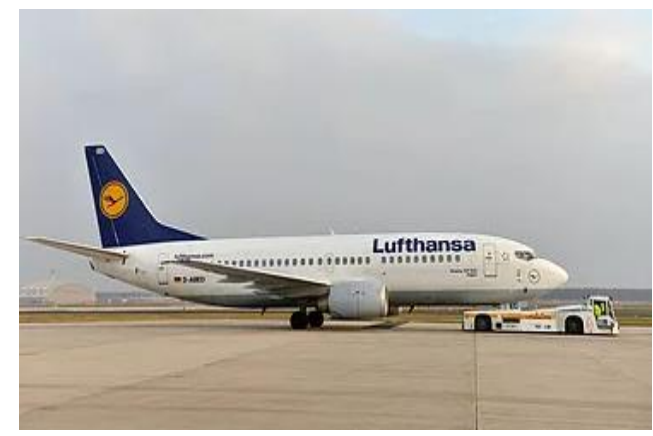

(a)

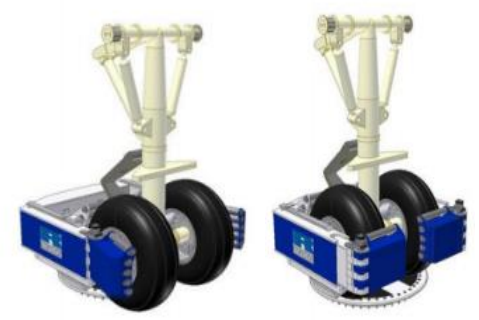

(b)

Fig. 5. Demonstration of TaxiBot (a) towing B737 at Frankfurt airport and (b) engagement mechanism to the NLG [41].

pushback operations, for returning the vehicle after the aircraft's take-off, and in case of an emergency. From a carbon footprint perspective, the hybrid nature of the traction system lowers both fuel consumption and greenhouse gas emission.

Nevertheless, the TaxiBot still does not fully comply with the carbon-neutral objective and its fuel consumption will be detailed later in the paper. To date, the TaxiBot system is the only certified and commercially-operational alternative taxiing solution [43]. Indeed, the certification for its use with the Boeing 737 was issued by the European Aerospace Agency (EASA) in November 2014. Since then, three narrow-body models have been operating for Lufthansa LEOS (i.e., ground handling company of Lufthansa) at Frankfurt International airport. In May 2017, the EASA also certified the TaxiBot for the Airbus A320 family. In October of the same year, the TaxiBox certification in the old continent was followed by the Federal Aviation Administration (FAA) certification for the Boeing 737 family. In October 2018, the TaxiBot was brought into service even at Delhi airport, with the goal of extending its motor pool up to 40 tractors to be employed at the busiest Indian airports in the next four years [44].

\section{B. On-Board ETSs}

On-board ETSs are one of the most interesting MEA/AEA concepts. Compared to the external ones, their implementation allows the aircraft to be entirely autonomous during all onground phases, including pushback, which potentially leads to shorter total taxiing times. Furthermore, it would considerably minimize the airport surface movements of towing tractors with respect to the adoption of external ETSs. However, the main drawback of on-board systems is represented by their impact on aircraft weight. Therefore, the benefits of the saved fuel while taxiing could be offset by higher fuel consumption during the airborne phase, as discussed in the following section. Another major challenge is the change and adjustment of the aircraft 
architecture, which requires considerable efforts in terms of development, certification, and legislation and it is not always seen favourably by the aircraft manufacturers.

As previously mentioned, a typical on-board system consists mainly of some type of electrical drive. The variances among on-board systems come from the different electrical drive system configurations, mechanical drivetrains, and energy sources used. Considering the literature, the features listed below have been identified as the fundamental characteristics to be addressed when describing on-board systems:

\section{- Electric drive system}

Both the NLG and MLG configurations have advantages and drawbacks. Hence, the selection between them is a trade-off study among many aspects. First of all, the NLG layout benefits from the larger available space, which is not the case of MLG due to the presence of the braking system. Despite the confined available space, the MLG carries around $90 \%$ of the aircraft weight, making it particularly appealing for the motor installation due to the higher available traction forces [45]. Thus, at severe weather conditions such as snow, ice, and rain, when the tyre-road adherence is weakened, the performance of the ETS installed inside the NLG would be problematic. In narrow-body aircraft, the MLG is equipped with four wheels, and theoretically, four electric motors could be mounted within the gears.

This potential solution would enhance the overall system redundancy, and at the same time, it would introduce greater flexibility in designing the TM, because the requirements can be scaled down by four times. However, the biggest challenge of installing the TMs within the MLG remains thermal management [46]. In fact, the heat is generated by both the aircraft brakes and the traction motors thus, the installation of appropriate and advanced cooling systems is required [47], [48]. Alternatively, if the brakes are fitted with the brake cooling fans (BCFs), which is usually the case with regional and short-haul aircraft, the BCFs could be merged with the TM cooling system allowing a better exploitation of the available space.

\section{- Mechanical drivetrain}

The mechanical integration between TM and aircraft wheel represents another distinctive characteristic of the on-board ETSs and direct-drive or geared configurations are the possible options. In the case of a geared system, the TM is connected to the wheel through a step-down gearbox, which enhances the torque applied to the aircraft wheel. Such configuration choice enables a lower TM's torque rating and thus more compact TM design, but this benefit comes at the cost of an extra mechanical device that increases the component count, decreases the reliability at the system level, and introduces the potential risk of mechanical jams. Contrarily, a direct-drive solution features a simpler drivetrain construction improving the overall system reliability.

In either integration approaches, the mechanical drivetrain should be able to handle the considerable wheel speed values established during landing and take-off phases. Under these conditions, the actual speed might exceed the TM $\mathrm{rated} /$ maximum speeds and the issue is more likely to occur when a geared system is considered, as the gearbox will amplify the speed at the TM shaft. When the system comprises permanent magnet (PM) machines, then over speeding becomes a critical issue. The PMs must be retained successfully at all speeds, regardless of the mechanical drivetrain configuration. A common practice to address this risk consists in adopting a retaining sleeve, which holds the PMs and protects them during the TM assembling stage [49].

Apart from the mechanical challenge/risk, landing and takeoff speeds might lead to heavy electrical stresses on the TM insulation system, in the event of PM TM [50]. In fact, the significant voltage will be induced in the TM windings and safety precautions need to be taken for preventing severe damages on the electric drive. For instance, a clutch, either mechanical or magnetic, might be installed to physically disengage the TM from the aircraft wheel (i.e., free wheel rotation).

As previously mentioned, although any other device placed between TM and wheel affects the system weight and its reliability, the clutch implementation might be easier in geared systems, since it could be integrated within the gearbox. As an alternative to the clutch installation, the PM TM windings could be 1) kept open or 2) short-circuited at power converter level, by acting on the appropriate switching devices. In the first strategy, since the PM TM windings are open, their insulation system should be able to withstand the induced back electromotive force (EMF) voltage. However, the enhancement of the insulation system (especially phase-to-ground insulation) will negatively impact the PM TM design by affecting the slot copper fill factor and the heat dissipation capability.

Conversely, in the second strategy (i.e., closing the switching devices belonging to the bottom or top legs' converter), the circulation of relatively high current generated by the induced back EMF might be a source of thermal overloads, PM magnet demagnetization and drag/braking torque [51]. All these aspects can be critical for reliability and safety requirements. Hence, the PM TM should be carefully designed for dealing with such challenges and performant thermal management is often an effective mitigation method [52].

\section{- Electrical energy source}

For on-board ETSs, electrical energy can be provided by sources already available on the aircraft, such as the APU starter/generator (S/G) and the integrated drive generator (IDG) driven by the main engine [6]. Considering the former electrical energy source, an obvious approach would consist in exclusively powering the ETS from the APU S/G, but precautions need to be taken to avoid any overload situation. Indeed, the rated capacity of B737's APU S/G is $90 \mathrm{kVA}$, while it is estimated that around $240 \mathrm{~kW}$ are needed for ET, when the aircraft speed is equal to 20 knots $(37 \mathrm{~km} / \mathrm{h})$ on a taxiway featuring $1.5 \%$ slope and $1.5 \%$ friction coefficient, assuming 80 t MTOW. Besides the power requirements discrepancy, the extra weight resulting from the cabling could represent a crucial disadvantage.

A "hybrid" solution, in which the input ET drive power is shared between APU and IDG [53], was then proposed to ensure the desired ET kinematic performance, but this idea was not widely accepted due to the involvement of main engines in ground operations. In fact, such solution contradicts to the engineless ET concept. Even though the APU consumes less 
fuel compared to the main engines, emissions during taxiing are still present. Therefore, alternatively, energy can be supplied 'more electrically' and 'greener' through 'localised' batteries and fuel cells (water as only waste) or a combination of all of them.

In the upcoming sub-sections four on-board ETSs, respectively developed by 1) WheelTug, 2) DLR System, 3) Safran/Honeywell and 4) Safran/University of Nottingham (UoN) are presented and discussed.

\section{1) WheelTug on-board ETS}

The successful operation of the on-board ETS was pioneered in 2005 by WheelTug, a Gibraltar based company, which suggested a retrofittable and removable ETS that incorporates two induction machines manufactured by Chorus Motors, and integrated into the NLG wheels [54], [55]. For this application, Chorus Motors selected and patented the so-call Meshcon drive, which consists of a high phase order inverter that is connected to a high phase order concentrated winding induction motor using a mesh connection, whose details are out of the scope of the paper, but they can be found in [56]. One of the benefits of this configuration, over traditional induction motor EDSs, is the possibility of exploiting the machine's full power at low speeds and thus, at low voltage. Therefore, high starting torque, able to accelerate the aircraft according to the kinematic requirements, can be developed. Further, the Meshcon drive features a variable ratio between voltage and frequency, which is electronically adjusted by the inverter during motor operations [56].

In terms of energy source, the WheelTug on-board ETS is powered by the APU S/G, whereas its mechanical drivetrain is characterized by a planetary gearbox [30]. The overall ETS weights $130 \mathrm{~kg}$ [57] featuring a maximum taxiing speed of approximately 9 knots $(16.7 \mathrm{~km} / \mathrm{h})$ against the 30 knots $(55.6$ $\mathrm{km} / \mathrm{h}$ ) normally reached in conventional taxiing [58].

The proof of concept of the WheelTug ETS was demonstrated in 2005 on a Boeing 767, as illustrated in Fig. 6, whilst the second test on ground was performed in 2010 to prove the system feasibility and availability in critical weather conditions [59]. Finally, a full in-wheel motor operation was taken public at Prague airport in 2012 using a Boeing 737 [60], [61].

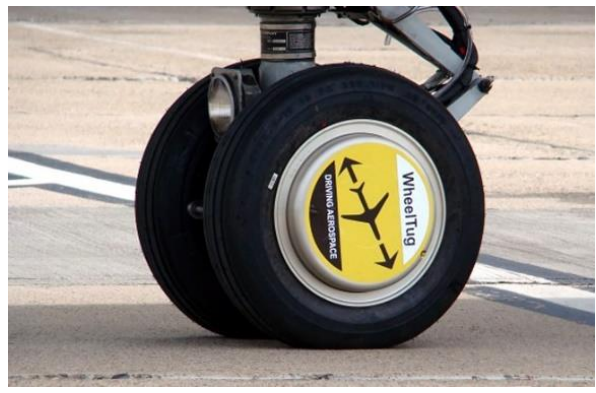

Fig. 6. WheelTug ETS implemented in NLG of B767.

The WheelTug ET on-board system is proposed to airlines through a power by hours lease type agreement along with all the necessary support, such as installation, maintenance, and even pilot's training [23], [54]. This indisputably impressive business model makes this system very attractive and it is not surprising that the company has more than 1200 orders from 20 airlines [31], even though they are still in the process of certification. Regarding the certification process, in January 2017, the FAA has approved WheelTug's plans for Boeing 737 NLG, while Air Transat has voluntarily offered to help with the related efforts [62]. For the future, Stirling Dynamics, a UK leader in landing gear development, has been chosen by WheelTug to design a new nose wheel for a better fitting of the TM [63].

\section{2) DLR on-board ETS}

Following the successful demonstration activities of WheelTug, developments of ETSs continued with other companies. The collaboration between the German Aerospace Centre DLR and Lufthansa Technik is one of them. The ETS was designed for an Airbus A320 aircraft and a NLG configuration. Two 3-phase, 16 poles, 24 slots, PM brushless DC motors are integrated in the NLG wheels [64]. Each TM generates a maximum torque of $400 \mathrm{Nm}$, allowing an aircraft on-ground top speed of $13.5 \mathrm{knots}(25 \mathrm{~km} / \mathrm{h})$ [65]. The actual torque applied to the wheel is enhanced by the geared nature of the DLR ET on-board system. Indeed, the TM is mechanically coupled to the wheel through a double stage planetary gear that provides an overall transmission ratio of 1:12. Hence, a maximum torque of $9.6 \mathrm{kNm}$ is available at the aircraft wheel, ensuring a satisfactory torque level in case of breakaway events. Furthermore, the double stage planetary gear, shown in Fig. 7, also embeds the clutch feature, which allows the free wheel rotation during landing and take-off stages [65]. This ETS was conceived to be powered from a fuel cell stack with a maximum power of $50 \mathrm{~kW} \mathrm{[66],} \mathrm{[67].} \mathrm{Due} \mathrm{to} \mathrm{the} \mathrm{naturally} \mathrm{low} \mathrm{voltage} \mathrm{of}$ the stack, a DC/DC converter was introduced to boost the voltage level up to $300 \mathrm{~V}$ [64].

The DLR ETS was tested in 2011 at Hamburg Finkerwerder airport on an Airbus A320 [68]. Despite the major perceived advantages, its bottleneck is represented by the fuel cells, which are still not technologically fully developed for mobile applications. In fact, there are still weight and safety issues associated with on-board hydrogen storage. At the moment, the most common technique to store hydrogen in traction applications is by using tanks that keep pressurised hydrogen gas at 700 bar. Unfortunately, the gravimetric weight density $\left(m_{\mathrm{H}_{2}} / m_{\text {tank }}\right)$ of those tanks is low, at around $5.5 \mathrm{wt} \%$, thus imposing additional weight concerns [69]. Further, fuel cells are still expensive due to their low production rate and they are characterized by a slow response that should be gapped through additional energy storage devices (i.e., battery and/or supercapacitor) to comply with the demanded acceleration rates.

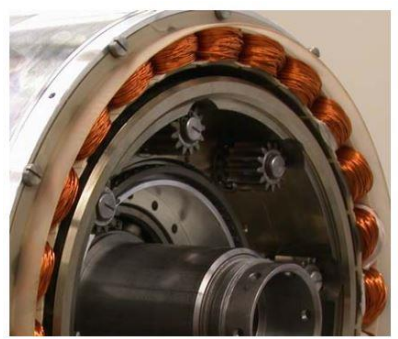

Fig. 7. DLR on-board ETS: view of the rotor with the rim-side double stage planetary gear [64]. 
3) Electric Green Taxiing System developed by Safran and Honeywell

In 2011, Safran and Honeywell Aerospace created a joint venture for launching a new aircraft taxiing system, called the Electric Green Taxiing System (EGTS), which was meant to be implemented in the aircraft MLGs. The EGTS is designed under the following requirements [70]:

1) to achieve a maximum speed of 20 knots $(37 \mathrm{~km} / \mathrm{h})$ for a time-window of $90 \mathrm{~s}$;

2) to obtain a speed of $10 \mathrm{knots}(18.5 \mathrm{~km} / \mathrm{h})$ in $20 \mathrm{~s}$ during active runway crossing;

3) to develop breakaway torque at full MTOW on a taxiway with $1.5 \%$ slope.

In Fig. 8(a), the overview of the implemented EDS is reported, and it comprises an autotransformer rectifier unit (ATRU), a wheel actuation control unit (WACU) and a TM. As can be observed, the ETS is powered through the APU, which also supplies hotel loads, such as lighting, entertainment, communication system, etc.

In terms of number of TMs, the EGTS utilizes one TM per MLG, hence two in total per aircraft. The deployed TM is 24 slots, 8 poles, inner rotor, three-phase, star connected, surface mounted PM synchronous machine (PMSM) and its total weight is $36 \mathrm{~kg}$ including the cooling fan (i.e., air-forced cooling system). The maximum torque produced during breakaway events is around $200 \mathrm{Nm}$, while $130 \mathrm{Nm}$ are available during acceleration phases [71]. The relatively low torque levels of the TM suggest that the EGTS is a geared system. WACU is a three-phase two-level inverter, whose DC link voltage values correspond to $\pm 270 \mathrm{~V}$, powered by a $40 \mathrm{~kW}$ continuous power ATRU [72]. Transient overload operations are permitted, since the ATRU features a peak power of $60 \mathrm{~kW}$. The EDS is vector controlled and the field weakening technique is implemented for extending the TM speed range up to 10 krpm.

The EGTS was successfully tested at the Paris International Air Show (PAS) in 2013 and its integration arrangement into the MLG of an Airbus A320 is depicted in Fig. 8(b). During the demonstration, a speed of only 10 knots $(18.5 \mathrm{~km} / \mathrm{h})$ was reached due to PAS safety regulations, but later on, 20 knots $(37 \mathrm{~km} / \mathrm{h})$ speed was achieved at Toulouse airport [71]. Even though the demonstration provided a positive outcome, Safran and Honeywell decided to terminate the EGTS project in 2016. However, Safran is today still devoted to the ET idea, through its involvement in the Clean Sky 2 framework. In particular, an optimum energy storage system up to TRL6 is under development by Safran Landing Systems, aiming at diminishing the dependency on the APU supply [73].

\section{4) Safran/UoN on-board ETS}

Safran also collaborated with the UoN, Airbus, Adeneo and DLR system under the CleanSky Joint Technology Initiative, for continuing the work of [66] and developing a direct-drive on-board ETS for MLG [74], [75]. The collaboration was primarily driven by the need for improving the ETS reliability, while minimizing its overall weight. Hence, the direct-drive solution appeared to be the most appropriate. Nevertheless, the implementation of the EDS inside the MLG represented the main challenge, due to the confined and limited space available in the gear cavity. Considering as benchmark aircraft an Airbus

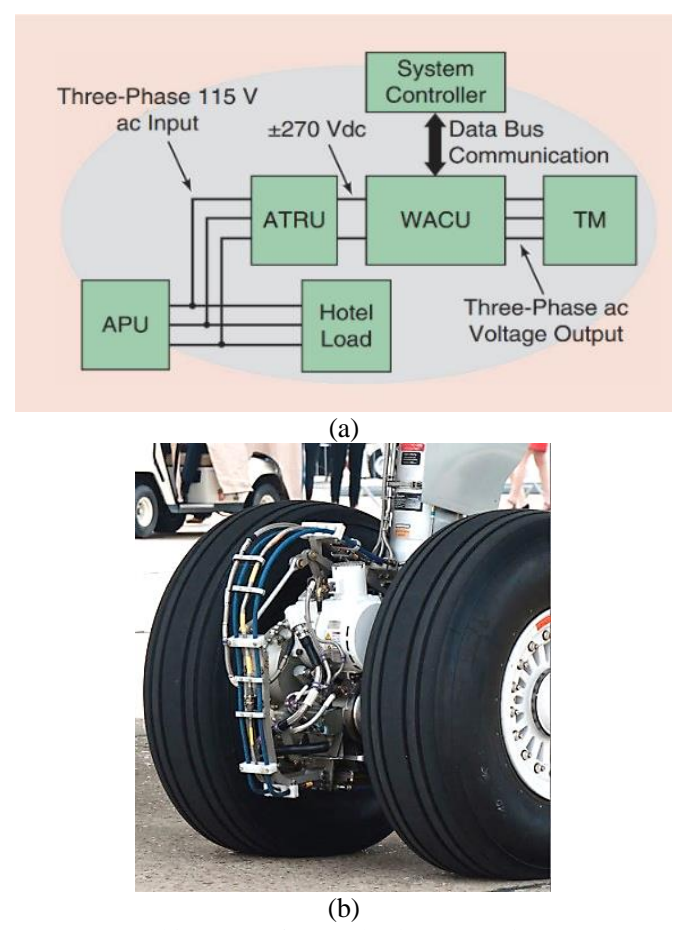

Fig. 8. EGTS (a) architecture of EDS (b) demonstration at PAS 2013 [72].

A320, the back and front envelopes of its MLG were identified as suitable locations for the TM, since two twin TMs could be fitted, as highlighted in Fig. 9. To deal with the demanding space requirements, a PMSM was selected as a result of the superior power density compared to others electrical machine topologies.

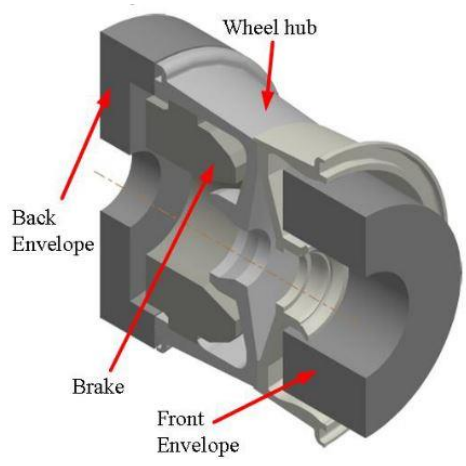

Fig. 9. MLG wheel visualisation [66].

The TM design process led to a machine featuring a recordholding peak torque density of $65 \mathrm{Nm} / \mathrm{kg}$ (where the number refers to the active weight of $108 \mathrm{~kg}$ with $7 \mathrm{kNm}$ peak torque) [75], resulting in a total torque at wheels of $14 \mathrm{kNm}$. These superb values were achieved through the implementation of several torque enhancement techniques [76]-[78]. Firstly, an outer rotor configuration was preferred to the more conventional inner rotor arrangement for the reasons listed below.

- Assuming electrical machines with similar performance characteristics, outer rotor motors are axially shorter than their inner rotor counterpart enabling a more compact design. - Comparing electrical machines with the same external overall diameter, the outer rotor configuration is characterized by a longer radius at the air gap compared to 
the inner rotor one (i.e., greater 'lever arm' for torque generation). Such particularity positively impacts the torque production, making the outer rotor appropriate for directdrive applications.

- The external rotor design leads to a larger rotor and thus to a higher moment of inertia that improves the damping action on the torque oscillations. This property delivers stable and smooth torque generation, also at relatively low speed levels (175 rpm is the TM rated speed). Although the higher moment of inertia featured by the TM (in outer rotor configuration) degrades the dynamic performance of the TM machine as standalone component, its impact on the overall ETS inertia is negligible. Indeed, the dynamic performance at system-level is ruled by the total inertia 'seen' at the TM shaft, whose most relevant contribution is given by the reflected aircraft inertia.

- Finally, a bigger rotor easies the coupling between motor and wheel for the specific application at hand.

Considering the PMs layout, a five-stage Halbach array configuration, represented in Fig. 10, was favoured because a stronger magnetic field is produced with the same PM volume. Hence, a higher flux density at the air gap is achieved, resulting in enhanced torque capability. Although the indisputable benefit of the Halbach array arrangement, it is also true that its employment adds manufacturing complexity and inflates the TM cost. Selection of materials played a critical role in pushing the torque density performance of the designed TM. In fact, advanced materials such as Cobalt Iron for the stator core laminations and Samarium Cobalt PMs were chosen. The former features very high saturation limits, thus extending the magnetic loading, while the latter provides outstanding performance at high operating temperatures. Indeed, due to the location of the TM at the MLG front envelope, only a forcedair cooling system was allowed as thermal management. Hence PMs are likely to experience high temperatures, which might be a source of demagnetisation issues.

Apart from the significant torque density level, the TM should ensure a satisfactory availability due to the safetycritical nature of the application under study. Therefore, a double star winding configuration (i.e., dual-channel power lane) was adopted to improve the fault-tolerant ability of the TM. The challenges caused by the landing and take-off speeds (refer to the section 'mechanical drive train' earlier discussed) were addressed by short-circuiting the TM winding terminals at power converter level. This strategy is feasible because the TM is designed according to a fault-tolerant approach. Indeed, the maximum absolute value of braking torque occurs at very low speed and the ensuing short-circuit current is contained below the TM rated value. Such design choice, on one hand, allows to mitigate the risks associated to the short circuit currents (i.e., over-temperature and permanent magnet demagnetisation), while, on the other hand, the resulting braking torque value at the aircraft landing and take-off speeds is relatively low (i.e., well below the TM rated torque). Thus, it can be easily overcame by the jet engines' thrust during take-off. The parameters of the manufactured TM are given in Table II, while the machine is shown in Fig. 11.

The proposed 36 slots/ 42 poles TM was first tested at the UoN laboratories using commercial power converters along

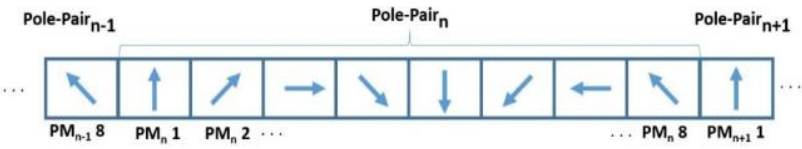

Fig. 10. Magnetisation direction of a 5-stage Halbach array configuration.

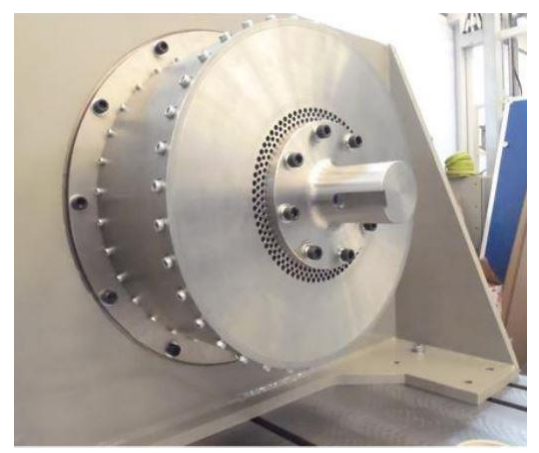

Fig. 11. The manufactured TM.

Table II. Parameters of the Safran/UoN on-board ETS TM.

\begin{tabular}{|c|c|}
\hline Parameter & Value \\
\hline Number of slots & 36 \\
\hline Number of poles & 42 \\
\hline Peak torque [kNm] & 7 \\
\hline Current at peak torque [Apk] & 223 \\
\hline Rated speed [rpm] & 175 \\
\hline DC link voltage [V] & 540 \\
\hline
\end{tabular}

with a dSPACE microcontroller platform. In Fig. 12, the assembled TM coupled on the testing angle plate is shown, where the gearbox is only used for testing purposes, in order to cope with the load machine rated torque. After the preliminary tests at UoN facilities, the TM was fed by the power electronics converters developed by Adeneo and controlled with the control algorithm written by DLR system. The second stage of the test campaign was carried out in Safran Landing Systems laboratories in France, where the whole EDS was tested up to TRL5 standards in a realistic environment. Currently, Safran is working with Airbus to take this technology to higher TRLs, intending to offer a market-ready, APU powered product for the future versions of the A320neo, branding it as 'e-taxiing' [79], [80].

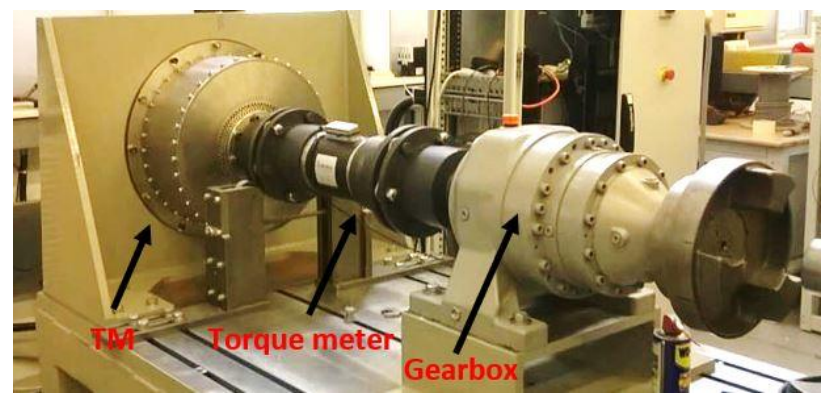

Fig. 12. The assembled TM on a test-bed at UoN. 


\section{ELECTRIC TAXIING SYSTEMS COMPARISON AND BENEFITS ASSESSMENT}

The ETSs presented in the previous section vary in many aspects, but especially in their configuration and technology. For this reason, their main features are summarized and compared in Table III, with the purpose of supporting the readers throughout this 'journey' among the recent research on ETSs and its development towards the implementation of the MEA concept. It is worthy to point out that it was not easy to collect all the desired information, due to their confidentiality and lack of public documentation on the topic. Therefore, the data collection did not always lead to a positive outcome. From Table III, it could be seen that NLG on-board ETSs (e.g. WheelTug and DLR) show lowest maximum taxiing speed compared to both MLG on-board and external ETSs. On the other hand, based on the available data, they are the cheapest with the most expensive one being the TaxiBot at a price of $\$ 1.5$ million (3 times the one of a conventional towing tractor [41]). Even though being the most expensive one, TaxiBot is operational and airlines are benefitting from using them since 2014. Conversely, on-board ETSs are still in the process of certifications (or even at the development/testing stage) and their manufacturers are promising market entry in the near future.

Regardless of the ETS configuration, the two most distinguishable features of ET against conventional taxiing are engineless and towbarless ground operations. The most significant benefit, which is strictly related to the adoption of engineless taxiing, is the minimization of fuel consumption and associated pollutions. Although the afore discussed systems are not completely emission and noise-free, they emit fewer pollutant gasses and noise with respect to both dual- and singleengine taxiing, due to the use of more efficient APUs and diesel engines. For instance, in approximatively 17 minutes of traditional taxiing, a Boeing 747 burns about $1 \mathrm{t}$ of fuel and releases $3.2 \mathrm{t}$ of $\mathrm{CO}_{2}$. Towing the same airplane to the runway with the TaxiBot system would consume less than 25-30 litres of diesel releasing about $60 \mathrm{~kg}$ of $\mathrm{CO}_{2}$, which is equivalent to a 98\% drop in $\mathrm{CO}_{2}$ [81]. Despite the considerable $\mathrm{CO}_{2}$ cutting, the external ETSs tend to generate more $\mathrm{NO}_{\mathrm{x}}$ compared to single-engine operation and on-board ETSs, since diesel engines are employed. Considering a dispatch towing scenario [27], where a fuel-based tug is used, the outlook is expected to be as detailed in the following. In case of diesel tugs, the jet fuel will be reduced by almost $75 \%$, while $\mathrm{CO}_{2}, \mathrm{HC}$, and $\mathrm{CO}$ emissions will be lowered by $70 \%, 40 \%$, and $72 \%$ on average respectively. However, the intrinsic nature of the diesel engine would actually increase the $\mathrm{NO}_{\mathrm{x}}$ emissions by a value between $70 \%$ and $120 \%$. Pursuing a mitigation of the $\mathrm{NO}_{\mathrm{x}}$ emissions, gasoline tugs have been suggested, but the general problem is not fully dealt because the $\mathrm{NO}_{\mathrm{x}}$ emissions mitigation is followed by an increment of both $\mathrm{CO}$ and $\mathrm{HC}$ emissions. Besides, the natural gas tugs have been also evaluated however, they would be generally unsuccessful for cutting down the emissions.

Although the fuel-based tugs can greatly reduce the greenhouse gas emissions, still the best results are achieved with the on-board ETSs. On this regard, detailed analyses on fuel and emissions reductions are discussed in [20], [82], [83]. In particular, [20] examines a study conducted for Zurich airport, where the implementation of on-board ETSs would result in $66 \%, 40 \%, 59 \%$, and $70 \%$ less generation of $\mathrm{CO}_{2}, \mathrm{NO}_{\mathrm{x}}$, $\mathrm{HC}$, and CO respectively. Nevertheless, it is essential and fair to highlight that the adoption of on-board ETSs does not always lead to fuel savings, due to the additional on-board weight.

The study conducted in [53] shows that block-fuel (i.e., taxi fuel + flight fuel) savings for sole aircraft are highly dependent on the total ground time and flight distance. As expected, with the same flight distance, the longer is the total ground time the higher is the total fuel saved, as reported in Fig. 13, where the flight distance is expressed in aeronautical mile ( $1 \mathrm{NM}=1.85$ $\mathrm{km}$ ). For instance, over a flight of $700 \mathrm{NM}$ (e.g., London to Madrid), fuel cut increases from $1 \%$ to $3 \%$, when the taxiing time rises from 14 to 22 minutes. In [19], a similar investigation was carried out taking into account Airbus A320 and Boeing 737 families, but applying data to all US domestic flight missions ran over 2007 by these aircraft. Such an approach allowed to attain the average overall fuel savings at the fleet level, which are estimated to be $1.1 \%$ in case the on-board ETS weights $1 \mathrm{t}$, whereas by decreasing the ETS weight down to 200

Table III. Quantitative comparison of the existing ETSs.

\begin{tabular}{|c|c|c|c|c|c|c|}
\hline Criteria & TaxiBot & LEKTRO & Wheel-Tug & DLR & EGTS & Safran* \\
\hline System Configuration & External & External (EP) & $\begin{array}{c}\text { On-board } \\
\text { (NLG + Geared) }\end{array}$ & $\begin{array}{c}\text { On-board } \\
\text { (NLG + Geared) }\end{array}$ & $\begin{array}{c}\text { On-board } \\
(\mathrm{MLG}+\text { Geared })\end{array}$ & $\begin{array}{c}\text { On-board } \\
(\mathrm{MLG}+\text { Direct Drive })\end{array}$ \\
\hline $\begin{array}{c}\text { Estimated time to enter } \\
\text { service }\end{array}$ & $\begin{array}{l}\text { Operational } \\
\text { since } 2014\end{array}$ & $\begin{array}{l}\text { Operational } \\
\text { since } 1990 \text { s }\end{array}$ & 2019 & N/A & Stopped in 2016 & 2021-2022 [80] \\
\hline On-board weight [kg] & - & - & $130-140$ & N/A & 400 (36 per TM) & $\begin{array}{c}\text { 320-380 est. } \\
(108 \text { per TM) [109] }\end{array}$ \\
\hline Max. power [kW] & 500 & 90 & N/A & 50 & 120 (90 cont.) & $120(60$ per TM) [109] \\
\hline Max. speed [knots] & 23 & 3.5 & 9 & 13.5 & 20 & 20 \\
\hline Towing capacity $[t]$ & $\begin{array}{l}68-85 \\
(\mathrm{~B} 737)\end{array}$ & $\begin{array}{c}127 \\
(\mathrm{~B} 757)\end{array}$ & N/A & $\begin{array}{c}78 \\
(\mathrm{~A} 320)\end{array}$ & $\begin{array}{c}78 \\
(\mathrm{~A} 320)\end{array}$ & N/A \\
\hline Cost & $\begin{array}{c}1.5-3 \\
\text { million [87] }\end{array}$ & $\begin{array}{c}\text { From } \\
\$ 159,00[38]\end{array}$ & $\begin{array}{c}\text { Power by hour } \\
{[54]}\end{array}$ & N/A & N/A & $\begin{array}{c}<\$ 1 \text { million per aircraft } \\
{[80]}\end{array}$ \\
\hline
\end{tabular}




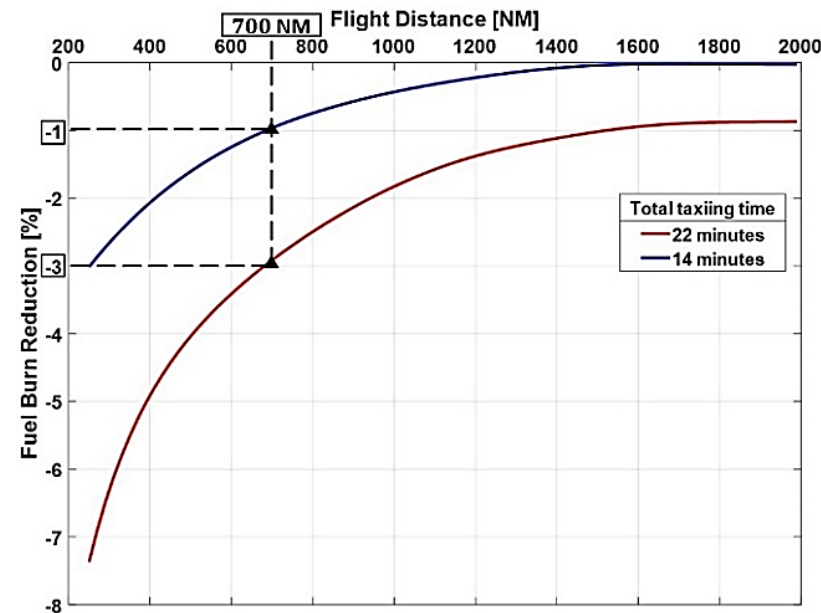

Fig. 13. Block-fuel reductions in respect to sector length and taxiing time [53].

$\mathrm{kg}$, a $3.9 \%$ fuel cutting is reached. Apart from the fuel consumptions, the commissioning of on-board ETSs would lower the noise levels by around 10-12 dB.

The simplification of the pushback procedure and the resultant contraction of the total pushback time are additional primary benefits of on-board ETSs. In Fig. 14(a) [54], sequential steps of the conventional pushback procedure are shown. It can be noticed that the backward motion of aircraft presents only a small fraction of the total pushback time. Thus, the implementation of on-board ETSs could directly eliminate most of the steps and simplify the overall pushback procedure, as visualized in Fig. 14(b). The time savings come from the fact that there is no need to wait for tugs and bars to be ready, connected, and disconnected. Furthermore, the absence of jet blasts at the gate area would lead to a streamlining of the issuing clearances from ground control. According to the WheelTug's survey, it is estimated that the average pushback time and the on-time performance will be 2 and 5 minutes respectively, against today's times of 8 and 20 minutes.

Besides the outlined explicit benefits of ET, many other implicit advantages do exist. For example, moving around the airport without the aircraft's engines on could lessen the risk of having the FOD, and accordingly lowering the engine maintenance costs. Other benefits include the improved lifetime (a)

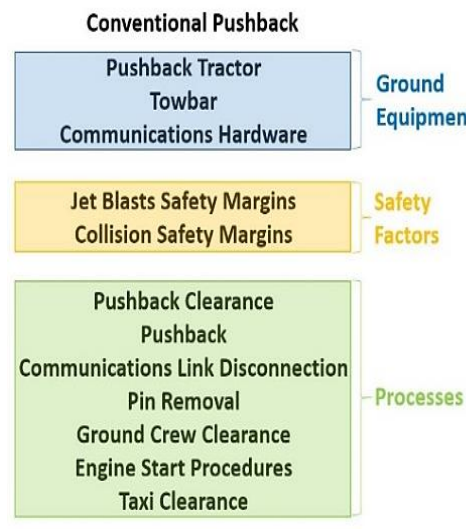

\section{On-board ETS Pushback}

Collision Safety Margins

Reverse and Taxi Clearance Reverse Operation

(b)
Fig. 14. Difference between conventional and electric pushback [54]. of brakes, due to the reduced carbon wear. In conventional taxiing, brakes are extensively used to maintain the desired speed. Contrarily, using ETSs, the velocity is easily controlled and there is no need for the brakes' over-usage. In addition, the health and safety of the ground operators will be enhanced since jet engine blasts would not be happening near the gates. Finally, WheelTug emphasizes the possibility of parking parallel to the terminal building. This option would, in turn, allow the use of two airport bridges for passengers boarding procedure, which would shorten the aircraft turnaround time. If this concept is to be applied on a bigger scale it will create new slots, resulting in reduced airport congestion [84].

From an economic point of view, the block-fuel and the time savings, along with the other subsequent effects, are likely to trigger a significant money saving that will influence and benefit the airlines, the airport management, and ultimately the passengers. For instance, from $\$ 66$ to $\$ 150$ per minute per turnaround can be saved just by eliminating the need to attach or detach towing tractors [83]. Based on the WheelTug's estimations, $\$ 385 \mathrm{k}$ per aircraft per year could be spared by installing their on-board ETS and such amount corresponds to $40 \%$ of the airline total fuel bill [23]. Considering the EGTS, the savings per aircraft per year are quantified between $\$ 240 \mathrm{k}$ and $\$ 283 \mathrm{k}$, depending on the EGTS utilization level. From its side, Safran is the company predicting the highest saving associated to the exploitation of on-board ETS, which might rise to $\$ 500 \mathrm{k}$ per aircraft per year [79]. Taking into concern the external ETSs, the IAI claims that using the TaxiBot (TB) could lead to $\$ 600$ saving per operation. Over an entire year, a total saving of $\$ 5.4$ million could be achieved if 25 operations per day are performed [41]. A summary of the ETSs benefits addressed in this section is provided in Table IV.

\section{Challenges AND RECOMMENDATIONS FOR FURTHER RESEARCH}

There are numerous technological, economic, legal, and operational challenges that hinder a wider implementation of ETSs. These challenges are discussed here from the perspective of ETS manufacturers, airlines, and airport operators. Additionally, according to the on-going research and trends in traction world, recommendations for future research are outlined for both external and on-board ETSs.

\section{A. Challenges}

Regarding the ground traffic operations, the impact of the average ET speed on the congestion of Schiphol Airport has been evaluated in [85]. An average taxiing speed of 19 knots $(35.2 \mathrm{~km} / \mathrm{h})$ was identified as the minimum speed which would not cause any further congestion. Lower average speeds could lead to additional delays to the aircraft behind them. Considering that the maximum achievable speed of all ETSs introduced in Section II is 23 knots $(42.6 \mathrm{~km} / \mathrm{h})$, most likely taxi-out and taxi-in times will slightly increase in case of ET. Hence, one of the challenges when implementing these systems is to try keeping the total ground time shorter or at least comparable to the one obtained through the conventional dualengine taxiing, in order not to compromise the passenger's contentment, as well as, the aspirations of airlines. Thus, these 
Table IV. ETSs: potential benefits comparison.

\begin{tabular}{|c|c|c|c|c|c|}
\hline Criteria & TaxiBot & Mototok & WheelTug & EGTS & Safran* \\
\hline $\begin{array}{l}\text { Pollution } \\
\text { reduction }\end{array}$ & $-98 \% \mathrm{CO}_{2}[81]$ & N/A & $\begin{array}{l}-60 \% \text { of total } \\
\text { emissions [57] }\end{array}$ & $\begin{array}{c}-47 \% \mathrm{NOx} \\
-62 \% \mathrm{CO}_{2} \\
-74 \% \mathrm{HC} \\
-74 \% \mathrm{CO}[70]\end{array}$ & $\begin{array}{c}-51 \% \mathrm{NOx} \\
-62 \% \mathrm{HC} \\
-61 \% \mathrm{CO}_{2} \\
-73 \% \mathrm{CO}[79]\end{array}$ \\
\hline Fuel reduction & $98 \%$ of taxi fuel [81] & $100 \%$ of pushback fuel & $50 \%$ of taxi fuel & $3 \%$ of block fuel [70] & $4 \%$ of block fuel [80] \\
\hline Time savings & N/A & $54 \%$ on pushback [35] & $6 \mathrm{~min}$ (average) & 2 min on pushback [70] & 2 min on pushback \\
\hline Money savings & $\$ 5.4 \mathrm{~m} \mathrm{py}^{+}$per TB & $\$ 100 k-236 k$ py [35] & $\$ 385 \mathrm{k}$ pa py & $\$ 240 k-283 k$ pa py & $\$ 250 k-500 k$ pa py \\
\hline
\end{tabular}

Data provided includes both e-taxiing and Safran/UoN projects; ${ }^{+}$per year (py), per aircraft (pa)

systems might not be beneficial in terms of taxiing time at airports where high taxiing speeds are required or when there is a clear path to the runway without frequent stop and go patterns. For this reason, WheelTug designers opted for low-speed ETS, since they estimate that the core saving comes from the simplified pushback procedure rather than from the whole taxiing process.

One of the technical issues with ETSs, whether it is an onboard or external one, is the jet engine warm-up and cool-down period. Namely, prior to take-off, engines must be warmed-up for 5 minutes before being fully loaded and cooled-down before being turned-off [86]. With conventional taxiing, this condition is automatically fulfilled, which is not the case with ET since the main engines are turned-off. Thus, engines must be turnedon at least 5 minutes before the take-off, for warming-up purposes. The engine check, start-up, and warm-up could be done while still taxiing electrically. Nevertheless, this potential solution can represent a safety hazard for the plane taxiing behind, due to the jet engine blast during start-up. Besides, even if there is no plane taxiing at the back, this option is questionable due to the APU power rating limitations. Indeed, APUs are not currently able to provide enough power to simultaneously supply the on-board ETS at maximum speed along with other electric loads, such as air conditioning and lighting, and air bleeding, knowing that the latter is necessary for the engine start-up. Therefore, as an alternative, a dedicated area near runway should be designed, where the aircraft could stop, switch off the ETS, and safely turn-on the engines. The introduction of such an area would further complicate taxiing procedures and airport infrastructures. Finally, it should be noted that the ET would not be beneficial at airports featuring taxiing time lower than 5 minutes, due to the engine warm-up.

Considering external ETSs, such as TaxiBot, the major challenge is of economic nature. In fact, there are two different types of TaxiBot and each of them only handles narrow- or wide-body aircraft. The first is expected to have a unit cost of approximately $\$ 1.5$ million, whereas the latter roughly prices $\$ 3$ million [87]. Ideally, this relatively high cost would be paid by the airport operators or handling companies, but the core financial benefit would be actually for the airlines. Such conflict of interest causes a high financial disproportion between the airport/handling company and the airline. On the topic, Lufthansa proposed a compromise, in which the TaxiBots would be purchased by airlines and operated by airline owned handling companies at their focus hub airports. The success of this option would primarily require an agreement among all or at the least the most prominent airlines, which is not an easy task to achieve. Further, the risk that small airports will not be covered by the agreement seems fair, as well as, the potential disputes between airlines to 'control' a specific airport. More details on this solution are given in [41]. An alternative option might be represented by some sort of special subsidies or agreements between the two parties. However, airports would still have to significantly invest in their road network infrastructure to account for the increased traffic of towing vehicles. The cost for additional concrete tracks is approximately $\$ 240$ per square meter, or alternatively asphalt can be used, which is $\approx 20 \%$ cheaper than concrete. Finally, potential fatigue to the aircraft nose wheel should be considered for any external tractor-type system, as the operation should be smooth to reduce stress on the nose wheel [83].

In regard to on-board ETSs, the MLG is perceived as a hostile environment for its installation, since the available space is very constrained and the proximity of the mechanical brakes represents an extra source of excess heat. Further, dust and breaks residues could block the air cooling passages, compromising the effectiveness of the thermal management. A supplementary challenge for the cooling of the on-board ETSs comes from the exposure to the harsh environment such as dust, moisture, water spray, etc., which should be addressed by environmentally sealing the TM. This extra layer of thermal insulation would make the TM thermal management even harder. Apart from the thermal side, mechanical stresses, such as landing shocks and operational vibrations, are aspects that should be carefully accounted at the design stage and they might lead to some changes in the MLG system.

Another important aspect to be considered for on-board ETSs is related to the low pilot's visibility of the surrounding area during pushback. A solution to this safety challenge will be implemented by some manufacturers, e.g. Wheeltug's ETS will have a 360 degree view camera system which will enable a wider visibility [88]. At the moment, no information has been disclosed about the testing of on-board ETSs during landing and take-off conditions. This means that on-board ETSs are currently in between TRL 6 and 7, which is expected due to the certification time.

The on-board ET solutions are the most suitable for aircraft flying many short-haul flights during the day between airports with high taxiing time. Nevertheless, the same plane could have different flight missions for the same airline operator. For instance, KLM's B737, which flies between London Heathrow and Amsterdam Schiphol, two of the busiest airports in Europe, 
might see the benefits of on-board system implementation, while no benefits would be discerned for the same aircraft flying between airports with shorter taxiing times and further apart. Thus, the overall average economic gains of carrying the weight of on-board ETS have to be justified for each aircraft model and route. The same concept applies to overall emissions reduction. Regarding long-haul flights (i.e., longer than 4000 NM), a more appropriate solution would be to use external ETSs. Therefore, the final decision will have to be made by the airline companies, in accordance with their network and aircraft utilization, since the type of ETS will significantly impact their operation. In theory, the increase in weight due to the addition of on-board system (ranging from 136 to $400 \mathrm{~kg}$ ) could be offset by a reduction of two or more passengers, as well as, by imposing a stricter baggage allowance. For on-board ETSs attached to the NLG, the additional weight would slightly offset the centre of gravity requiring further attention to the aircraft balancing [83]. These uncertainties make airline reluctant to select only one ETS and consequently the widespread market entering of the ETSs is delayed.

\section{B. Recommendations}

In light of all the topics discussed and presented so far, it can be inferred that further research is necessary to overcome the challenges. In the process of further developments into MEA and AEA, the ever-stringent requirements imposed to the aerospace industry will lead to the implementation of a number of enhancement solutions, in order to make ETSs a viable technology for taxiing.

\section{1) External ETSs}

Regarding external solutions, currently, there is a cooperation between NASA, TaxiBot, and other institutions to move the TaxiBot into an autonomous, driverless system [89]. This would provide further advantages in terms of safety and operation logistics including 1) elimination of possible misscommunications, 2) boosted safety for the ground crew, 3) decreased delays with logistics planning, 4) improvements in coordination with ramp and tower control, 5) reduced workload on pilots, and 6) personnel cost cuts. Moreover, EP systems can be considered as a stepping stone between the hybrid and fully electric external ETS. Henceforth, it is recommended to investigate the development of fully electric external towing trucks, since this option would remove the need for fossil fuels, and it would completely eliminate greenhouse gas emissions during taxiing.

\section{2) On-Board ETSs}

As a general limitation of the on-board ETSs, the installation space should be addressed by designing ever-more power-dense devices. Furthermore, the focus should also be given on improving reliability, fault tolerance capability, efficiency, controllability, thermal robustness, complexity of design, and ease of fabrication [11], [90], [91]. In the following paragraphs, these considerations will be covered for all the essential aspects of on-board ETSs.

\section{a) Electro-Mechanical Drive System}

Up to now, only radial flux TMs have been employed in the proposed ETSs. Axial flux PM (AFPM) configurations could also be considered as potential candidates for the ET, since they feature an inherently easier integration to the wheel. A study conducted in [92] explored this motor configuration for commercial mid-sized aircraft ET application. The motor was designed considering an on-board MLG configuration with four TMs, each of them being connected to the wheels through a gearbox with a ratio of $1: 12$. This study showed that the designed AFPM machine was able to achieve the required ET performance for an Airbus A321, while maintaining an efficiency of $97 \%$. Compared to other proposals for MLG configurations, this is a very high efficiency value, which proves that AFPM solutions are promising candidates for future research.

In general, it is perceived that improvements on power/torque density can be achieved through innovative thermal and mechanical management techniques [93]. Due to the nature of the in-wheel installations, natural or forced air cooling methods are the most convenient heat extraction techniques. So, in order to push the boundaries of these cooling methods, advanced and unconventional solutions need to be deployed, such as the usage of thermal heat path [94], the back iron extensions [95] or the phase change materials [96].

From a more system-level perspective, an innovative solution to replace the clutch system is presented in [97]-[100]. A conical two degrees of freedom induction machine, whose shape and geometry permit both rotational and axial movements, would eliminate the need for the mechanical clutch and the ensuing challenges associated to it, such as the need for accurate synchronization between wheel and TM. Further, the PM machines with two degrees of freedom could also be employed, such as those presented in [101]-[104].

Looking more into the future of MEA and AEA, there are suggestions to increase the rated voltage level of the aircraft electrical power system up to the ranges of $2-4 \mathrm{kV}$ ( $\mathrm{AC}$ and DC) [105]-[108]. High system voltage level could leverage the possibility of more efficient and power-dense EDSs. In aerospace applications, there are already motors that are operating beyond $540 \mathrm{~V}$. Example of these motors are used for propulsion of small electric aircraft operating at 800 and 700 VDC, manufactured by Rotex and ENSTROJ respectively [109].

Nevertheless, until these new systems are accepted and certified for commercial passenger aircraft, it is fair to argue that it could be acceptable to operate at higher voltages during ET application. This is due to the fact that the ET is only operational at ground level, where the effect of low pressure at high altitude on the partial discharge inception voltage (i.e., Paschen's law) is absent and the electrical insulation is speared by this additional stress, unless landing/taxiing is to take place at areas of high altitude and low pressure. However, the DC link voltage can have transients much higher than the declared rated values (i.e., $2-4 \mathrm{kV}$ ). These phenomena could lead to overvoltages observed at the TM terminals, eventually accentuated by the characteristic impedance mismatch between cables and motor windings and by the elevated voltage gradients coming from the converter output. Therefore, careful design/selection of the cabling, power converters and TM must be performed, as the voltage values at the TM terminals can be very close or even overcome the partial discharge inception voltage during transients. 
For on-board ETSs to be competitive, they have to be cost effective, which can be achieved if the weight is more optimized and reduced, as explained in the previous section. For example, the two TMs of the EGTS weight $72 \mathrm{~kg}$, while $400 \mathrm{~kg}$ is the weight of the whole system. The remaining $328 \mathrm{~kg}$ (i.e., $82 \%$ ) are divided among the mechanical interface, cabling, power converters, and protection devices. Hence, the target for future systems needs to focus on the optimization of the associated sub-systems.

The proposed boosted voltage levels will lead to lower current values for the same rated power. Thus, the cabling weight is likely to be considerably reduced, as well as the Joule losses per unit of cable length. Similarly, the adoption of the new wide bandgap devices, such as Silicon Carbide $(\mathrm{SiC})$ and Gallium Nitrate (GaN), could help to reduce the weight, volume and losses of the power converters [110]-[113]. Additionally, the $\mathrm{SiC}$ semiconductors give prominence to higher temperature capability compared to conventional devices. Based on [114], the application of $\mathrm{GaN}$ in the aerospace field could 1) cut down the power converter losses up to $50 \%, 2$ ) compact its design with a two-third volume reduction, and 3) increase by three times the operating frequency. Moreover, some variations of Zsource inverters can ensue in a smaller size for both the power converter itself and its heat sink [115].

\section{b) Electrical Energy Source}

The rise of power level requested from the APU represents an actual challenge for the future of the on-board ETSs. Such demand could be solved by redesigning the APU, in order to power new ET and other common aircraft electrical loads and at the same time providing enough bleed air for engine start-up. This would, in turn, make the adoption of on-board ETSs even more unfavorable and costly for both the aircraft manufacturers and airlines. Also, powering on-board systems from the APU would mean extra cabling weight of estimated $60 \mathrm{~kg}$ for an A320 aircraft. Thus, the future looks towards the most viable option to take the form of a local energy storage system (LESS). Installation of a LESS would not only reduce the dependency from the APU, which will not be redesigned, but it would also allow the energy to be harvested during braking events. Such an initiative would improve the overall performance of the EDS, while lowering the APU generated emissions.

In [116], [117], the impact of regenerative braking on energy consumption was investigated and an average $15 \%$ reduction of the demanded tractive energy was assessed. Nevertheless, the benefits introduced by the LESS unit come at the price of extra weight, which will be carried throughout the airborne phase of the flight. For instance, considering a LESS unit meant only for regeneration purposes during ET, it should fulfil a target mass of $40 \mathrm{~kg}$, according to the Clean Sky 2 project [73].

Currently, the energy storage devices play a key role in achieving the complete emission-free ET, i.e., LESS would behave as a sole provider of the power and energy required for the ET. Considering the power and energy requirements of the ET together with the specific energies and powers of the available energy storage technologies, Li-ion batteries and super-capacitors arise as the most suitable candidates for targeting the full ET goal. Nevertheless, these devices should be as compact and light as possible and research efforts are presently invested on the subject. Indeed, promising novel devices, able to comply with these requirements, are under study and their research aims at combining the characteristics of both batteries and supercapacitors into a single apparatus, giving birth to the so-called supercapatteries and supercabatteries [118]. Furthermore, novel chemistries emerge in the battery world, such as Li-air and Li-florid batteries. Their energy densities are encouraging, since they can theoretically be as high as 5200 and $6235 \mathrm{Wh} / \mathrm{kg}$ [119] compared to 250 $\mathrm{Wh} / \mathrm{kg}$ of Li-ion chemistries.

Although the research path towards the enhancement of both specific power and energy appears to be outlined, some 'collateral' issues related to the adoption of LESS in aerospace applications demand further examinations. In fact, the energy storage lifetime at altitude and under heavy duty-cycles needs to be properly addressed through accurate lifetime prediction models, as well as, the risk of explosion and the LESS disposal once its useful life has come to an end. All these possibilities are just one direction in which future works regarding energy storage can move.

\section{CONCLUSIONS}

Global aviation challenges have shaped the technology development in which the aerospace industry moves towards a greener and more fuel-efficient aircraft utilization. Ground operations are not exempted from those initiatives and in fact, all taxiing procedures are required to be carbon-free by 2050 . In line with these requirements, many ETSs have been recently proposed and this paper presents a comprehensive review of developed and successfully tested systems, at both componentand system-levels. It includes a description of various topologies and it highlights their advantages and disadvantages. Furthermore, the environmental and economic benefits of specific ETSs are assessed and compared in detail. Finally, some implementation challenges are discussed and suggestions for future research are given.

In summary, the choice of ETS is a trade-off, which depends upon cost, ease of implementation, kinematic performance, and both fuel and time savings. However, it can be concluded that at the moment, none of the presented systems has achieved any significant performance gap compared to other competitors. Even though the three most prominent systems (i.e., TaxiBot, WheelTug, and Safran ETSs) have different concepts, all of them claim similar environmental and economic benefits. A clear view of which ETS is optimal for a particular situation/scenario will be achieved only when these systems massively enter the market and when further airline demands drive the technology innovations.

However, it is also equally true that until AEA ultimately drive conventional and MEA out of market, something which is still way too far in the future, then the implementation of ETSs is a necessity for future aircraft to meet the 2050 targets, in terms of optimisation of travel and to be compliant with emissions policies. Nevertheless, a realistic prediction based on the most promising ETSs available today would foresee the following scenarios:

1) No major savings in terms of total taxiing time. 
2) A potential reduction of block-fuel burns in the range of 1$4 \%$, depending on the flight distance and the weight of onboard ETS.

3) There could be savings from as low as $\$ 50 \mathrm{k}$ up to $\$ 500 \mathrm{k}$ per year per aircraft.

4) The maximization of the advantages arising from the adoption of ETSs can be accomplished by alternating the employment of external and on-board ETSs, based on the airline fleet capability and the airports' characteristics.

Finally, it is still predicted and proved that reasonable reductions in $\mathrm{CO}_{2}, \mathrm{CO}$, and $\mathrm{HC}$ emissions are possible, thus leading to the cutback of the associated cost penalties (taxes) nowadays in place. This would actually make a big part of the total savings. Yet, the $\mathrm{NO}_{\mathrm{x}}$ emissions lowering is still the challenging task to address. Overcoming the technical, legal, and operational obstacles, would also accelerate the advancements of greener taxiing operations.

\section{REFERENCES}

[1] "Air transport Action Group - Facts and Figures." [Online]. Available: https://www.atag.org/facts-figures.html. [Accessed: 17Jul-2019].

[2] "Reducing emissions from aviation." [Online]. Available: https://ec.europa.eu/clima/policies/transport/aviation_en\#tab-0-0. [Accessed: 17-Jul-2019].

[3] "Information on aviation's environmental impact." [Online]. Available:

https://publicapps.caa.co.uk/docs/33/cap1524environmentalinformat ion29032017.pdf. [Accessed: 17-Jul-2019].

[4] European Comission, "Annual Analyses of the EU Air Transport Market 2016." [Online]. Available: https://ec.europa.eu/transport/sites/transport/files/2016_eu_air_trans port_industry_analyses_report.pdf. [Accessed: 17-Jul-2019].

[5] Airbus, "Global Market Forecast: Global Networks, Global Citizens 2018-2037," 2018. [Online]. Available: https://www.airbus.com/aircraft/market/global-marketforecast.html. [Accessed: 17-Jul-2019].

[6] V. Madonna, P. Giangrande, and M. Galea, "Electrical Power Generation in Aircraft: Review, Challenges, and Opportunities," IEEE Trans. Transp. Electrif., vol. 4, no. 3, pp. 646-659, 2018.

[7] European Comission, "Flightpath 2050, Europe's Vision for Aviation." [Online]. Available: https://ec.europa.eu/transport/sites/transport/files/modes/air/doc/flig htpath2050.pdf. [Accessed: 17-Jul-2019].

[8] EASA, EEA, and EUROCONTROL, "European Aviation Environmental Report 2019,” 2019. [Online]. Available: https://www.eurocontrol.int/sites/default/files/2019-06/eaer2019_0.pdf. [Accessed: 17-Jul-2019].

[9] "Jet Fuel Price Monitor." [Online]. Available: https://www.iata.org/publications/economics/fuelmonitor/Pages/index.aspx. [Accessed: 17-Jul-2019].

[10] P. Giangrande et al., "Considerations on the development of an electric drive for a secondary flight control electromechanical actuator," Press IEEE Trans. Ind. Appl. DOI 10.1109/TIA.2019.2907231, pp. 1-1, 2019.

[11] W. Cao, B. C. Mecrow, G. J. Atkinson, J. W. Bennett, and D. J. Atkinson, "Overview of electric motor technologies used for more electric aircraft (MEA)," IEEE Trans. Ind. Electron., vol. 59, no. 9, pp. 3523-3531, 2012.

[12] X. Roboam, B. Sareni, and A. De Andrade, "More Electricity in the Air," Ind. Electron. Mag. IEEE, vol. 6, no. 4, pp. 6-17, 2012.

[13] M. Lukic et al., "State of the Art of Electric Taxiing Systems," 2018 Int. Conf. Electr. Syst. Aircraft, Railw. Sh. Propuls. Road Veh. Int. Transp. Electrif. Conf., pp. 1-6, 2018.

[14] ICAO, "ECCAIRS Aviation - Data Definition Standard." [Online]. Available:

https://www.icao.int/safety/airnavigation/AIG/Documents/ADREP

Taxonomy/ECCAIRS Aviation 1.3.0.12 (VL for AttrID 391 - Event Phases).pdf. [Accessed: 17-Jul-2019].
[15] ICAO, Annex 14, Volume I, Aerodrome Design and Operations, vol. I, no. July. 2018.

[16] "Airport CDM Implementation - The Manual." [Online]. Available: https://www.eurocontrol.int/sites/default/files/publication/files/airpo rt-cdm-manual-2017.PDF. [Accessed: 17-Jul-2019].

[17] H. Khadilkar and H. Balakrishnan, "Estimation of Aircraft Taxi Fuel Burn Using Flight Data Recorder Archives," in AIAA Guidance, Navigation, and Control Conference, 2011.

[18] "Federal Aviation Administration (FAA) New York - John F. Kennedy International Airport." [Online]. Available: https://www.faa.gov/nextgen/snapshots/airport/?locationId=34.

[Accessed: 17-Jul-2019].

[19] N. Dzikus, J. Fuchte, A. Lau, and V. Gollnick, "Potential for Fuel Reduction through Electric Taxiing," in 11th AIAA Aviation Technology, Integration, and Operations (ATIO) Conference, 2011.

[20] E. Fleuti and S. Maraini, "Taxi-Emissions at Zurich Airport," 2017. [Online]. Available: https://www.zurich-airport.com/thecompany/noise-policy-and-the-environment/air-quality. [Accessed: 17-Jul-2019].

[21] P. Vaishnav, "Costs and Benefits of Reducing Fuel Burn and Emissions from Taxiing Aircraft," Transp. Res. Rec., vol. 2400, no. 1, pp. 65-77, 2014.

[22] "TLD.” [Online]. Available: https://www.tld-group.com/. [Accessed: 17-Jul-2019].

[23] "WheelTug Webinar: Cheaper, Safer, and More Comfortable - You Can Have All Three!" [Online]. Available: http://media.wheeltug.com/. [Accessed: 20-Apr-2019].

[24] L. Khammash, L. Mantecchini, and V. Reis, "Micro-simulation of airport taxiing procedures to improve operation sustainability: Application of semi-robotic towing tractor," 5th IEEE Int. Conf. Model. Technol. Intell. Transp. Syst. MT-ITS 2017 - Proc., pp. 616621, 2017.

[25] J. Chen, M. Weiszer, P. Stewart, and M. Shabani, "Toward a More Realistic , Cost-Effective , and Greener Ground Movement Through Active Routing - Part I : Optimal Speed Profile Generation," IEEE Trans. Intell. Transp. Syst., vol. 17, no. 5, pp. 1196-1209, 2016.

[26] R. Guo, Y. Zhang, and Q. Wang, "Comparison of emerging ground propulsion systems for electrified aircraft taxi operations," Transp. Res. Part C Emerg. Technol., vol. 44, pp. 98-109, 2014.

[27] I. D. H. Balakrishnan, "Evaluation of strategies for reducing taxi-out emissions at airports," Proc. 10th AIAA Aviat. Technol. Integr. Oper. Conf. (ATIO 2010), Fort Worth, Texas, 2010.

[28] P. Giangrande, V. Madonna, G. Sala, A. Kladas, C. Gerada, and M. Galea, "Design and testing of PMSM for aerospace EMA applications," Proc. IECON 2018 - 44th Annu. Conf. IEEE Ind. Electron. Soc., vol. 1, pp. 2038-2043, 2018.

[29] C. I. Hill, S. Bozhko, T. Yang, P. Giangrande, and C. Gerada, "More Electric Aircraft Electro-Mechanical Actuator Regenerated Power Management," IEEE Int. Symp. Ind. Electron., vol. 2015-Septe, pp. 337-342, 2015.

[30] J. Tao, J. Guo, and C. Liu, "A review of powered wheel for aircraft," 2016 IEEE Int. Conf. Aircr. Util. Syst., pp. 378-383, 2016.

[31] "WheelTug." [Online]. Available: http://www.wheeltug.com/news.php . [Accessed: 20-Apr-2019].

[32] "Boeing Demonstrates New Technology for Moving Airplanes on the Ground." [Online]. Available: https://boeing.mediaroom.com/200508-01-Boeing-Demonstrates-New-Technology-for-Moving-

Airplanes-on-the-Ground. [Accessed: 17-Jul-2019].

[33] J. Hospodka, "Cost-benefit analysis of electric taxi systems for aircraft," J. Air Transp. Manag., vol. 39, pp. 81-88, 2014.

[34] I. Chakraborty, M. J. LeVine, M. Hassan, and D. N. Mavris, "Assessing Taxiing Trade Spaces from Aircraft, Airport, and Airline Perspectives," in 15th AIAA Aviation Technology, Integration, and Operations Conference, 2015.

[35] "Mototok." [Online]. Available: https://www.mototok.com/. [Accessed: 17-Jul-2019].

[36] "Charlatte America." [Online]. Available: https://www.charlatteamerica.com/. [Accessed: 17-Jul-2019].

[37] "Eagle Tugs." [Online]. Available: https://eagletugs.com/. [Accessed: 17-Jul-2019].

[38] "Lektro." [Online]. Available: https://www.lektro.com/. [Accessed: 17-Jul-2019].

[39] "Aircraft Tractors Driven from the Cockpit Save Thousands of Tons of Fuel." [Online]. Available: https://www.innovationsreport.com/html/reports/energy-engineering/aircraft-tractors-driven- 
from-the-cockpit-save-thousands-of-tons-of-fuel.html. [Accessed: 17-Jul-2019].

[40] "TaxiBot-International." [Online]. Available: http://www.taxibotinternational.com/. [Accessed: 17-Jul-2019].

[41] H. Jakub, "Electric taxiing - Taxibot system," MAD - Mag. Aviat. Dev., pp. 17-20, 2014.

[42] "Pilot controlled dispatch towing - without engines running." [Online]. Available: http://www.lufthansa-leos.com/taxibot. [Accessed: 17-Jul-2019].

[43] "TaxiBot - Green revolution in airplane taxiing." [Online]. Available: http://docs.wixstatic.com/ugd/865bf2_9eb200929c4a42108ecf23d94 e5c1379.pdf. [Accessed: 17-Jul-2019].

[44] "TaxiBot in India." [Online]. Available: http:/taxibotindia.com/news/. [Accessed: 17-Jul-2019].

[45] I. Chakraborty, D. R. Trawick, D. N. Mavris, M. Emeneth, and A. Schneegans, "A Requirements-driven Methodology for Integrating Subsystem Architecture Sizing and Analysis into the Conceptual Aircraft Design Phase," in 14th AIAA Aviation Technology, Integration, and Operations Conference, 2014.

[46] Z. Xu et al., "Thermal management of a permanent magnet motor for an directly coupled pump," 2016 XXII Int. Conf. Electr. Mach. (ICEM), Lausanne, 2016, pp. 2738-2744.

[47] V. Madonna, P. Giangrande, A. Walker, and M. Galea, "On the Effects of Advanced End-Winding Cooling on the Design and Performance of Electrical Machines," Proc. - 2018 23rd Int. Conf. Electr. Mach. ICEM 2018, pp. 311-317, 2018.

[48] V. Madonna, A. Walker, P. Giangrande, G. Serra, C. Gerada, and M. Galea, "Improved thermal management and analysis for stator endwindings of electrical machines," IEEE Trans. Ind. Electron., vol. 66, no. 7, pp. 5057-5069, 2019.

[49] P. Giangrande, A. Al-Timimy, A. Galassini, S. Papadopoulos, M. Degano, and M. Galea, "Design of PMSM for EMA Employed in Secondary Flight Control Systems," 2018 IEEE Int. Conf. Electr. Syst. Aircraft, Railw. Sh. Propuls. Road Veh. Int. Transp. Electrif. Conf. ESARS-ITEC 2018, pp. 1-6, 2019.

[50] V. Madonna, P. Giangrande, W. Zhao, H. Zhang, C. Gerada, and M. Galea, "On the Design of Partial Discharge-Free Low Voltage Electrical Machines," in 2019 IEEE International Electric Machines \& Drives Conference (IEMDC), 2019, pp. 1837-1842.

[51] P. Giangrande, V. Madonna, S. Nuzzo, and M. Galea, "Design of Fault-Tolerant Dual Three-Phase Winding PMSM for Helicopter Landing Gear EMA," in 2018 IEEE ESARS-ITEC, 2018, pp. 1-6.

[52] V. Madonna, P. Giangrande, C. Gerada, and M. Galea, "Thermal analysis of fault-tolerant electrical machines for aerospace actuators," IET Electr. Power Appl., vol. 13, no. 7, pp. 843-852, 2019.

[53] Y. Nicolas, "eTaxi, taxiing aircraft with engines stopped." [Online]. Available: http://www.smartcockpit.com/docs/taxiing-aircraft-withengines-stopped.pdf. [Accessed: 06-Aug-2019].

[54] "IATA E-Taxi Conference 2017 Presentation - WheelTug Media." [Online]. Available: http://media.wheeltug.com/. [Accessed: 20-Apr2019].

[55] "Chorus Motors." [Online]. Available: http://www.chorusmotors.com/aerospace.php. [Accessed: 17-Jul2018].

[56] "Chorus Meschon Technology." [Online]. Available: http://www.chorusmotors.com/technology/MeshconDerivation.pdf. [Accessed: 20-Apr-2019].

[57] D. Švragulja, "Masures for improving fuel efficiency by implementing electric taxi system," Msc Thesis Study Univeristy Zagreb, 2015.

[58] S. Soepnel and P. C. Roling, "Impact of Electric Taxi Systems on Airport Apron Operations and Gate Congestion at AAS," Msc Thesis Study Delft Univ. Technol., 2015.

[59] "WheelTug® Tow Tests Successful in Prague." [Online]. Available: http://www.marketwired.com/press-release/wheeltugr-tow-testssuccessful-in-prague-1364008.htm. [Accessed: 17-Jul-2019].

[60] "WheelTug Successfully Tests Electric Drive System on Boeing 737NG." [Online]. Available: http://www.marketwired.com/pressrelease/wheeltug-successfully-tests-electric-drive-system-onboeing-737ng-1672869.htm. [Accessed: 17-Jul-2019].

[61] "WheelTug June 2012 Prague Ground Tests." [Online]. Available: https://www.youtube.com/watch?v=vfueF1iQrz4. [Accessed: 17Jul-2019].

[62] "WheelTug reveals timeframe for planned service entry." [Online]. Available: https://www.flightglobal.com/news/articles/wheeltug- reveals-timeframe-for-planned-service-entry-432956/. [Accessed: 17-Jul-2019].

[63] "STIRLING REDESIGNS THE WHEEL!" [Online]. Available: https://www.stirling-dynamics.com/news/stirling-redesigns-wheel/. [Accessed: 17-Jul-2019].

[64] M. Schier, F. Rinderknecht, A. Brinner, and H. Hellstern, "High Integrated Electric Machine for Aircraft Autonomous Taxiing," Int. Conf. Electr. Veh. Renew. Energies (EVER 11), 2011.

[65] M. Schrier, F. Rinderknecht, and H. Hellstern, "Electric Wheel Hub Motor for Aircraft Application," Int. J. Renew. Energy Res., vol. 1, no. 4, pp. 298-305, 2011.

[66] T. Raminosoa, T. Hamiti, M. Galea, and C. Gerada, "Feasibility and electromagnetic design of direct drive wheel actuator for green taxiing," IEEE Energy Convers. Congr. Expo. Energy Convers. Innov. a Clean Energy Futur. ECCE 2011, Proc., pp. 2798-2804, 2011.

[67] F. Re, "Viability and state of the art of environmentally friendly aircraft taxiing systems," in 2012 Electrical Systems for Aircraft, Railway and Ship Propulsion, 2012, pp. 1-6.

[68] "DLR Airbus A320 ATRA taxis using fuel cell-powered nose wheel for the first time." [Online]. Available: https://www.dlr.de/dlr/en/desktopdefault.aspx/tabid10204/296_read-931/\#/gallery/2078. [Accessed: 17-Jul-2019].

[69] T. Q. Hua, H. S. Roh, and R. K. Ahluwalia, "Performance assessment of 700-bar compressed hydrogen storage for light duty fuel cell vehicles," Int. J. Hydrogen Energy, vol. 42, no. 40, pp. 25121-25129, 2017.

[70] "EGTS." [Online]. Available: https://www.arts-etmetiers.asso.fr/manifestation_cr/678_compte_rendu.pdf . [Accessed: 06-Aug-2019].

[71] G. Evgeni, C. Chiang, L. Fizer, and E. Johnson, "Electric Drives for Electric Green Taxiing Systems," SAE Int. J. Aerosp., vol. 9, no. 1, pp. 62-73, 2016.

[72] E. D. Ganev, "Electric Drives for Electric Green Taxiing Systems: Examining and Evaluating the Electric Drive System," IEEE Electrif. Mag., vol. 5, no. 4, pp. 10-24, 2017.

[73] European Comission (March 2017), "Annex VI: 6 th Call for Proposals ( CFP06 ) - List and Full Description of Topics." [Online]. Available: https://ec.europa.eu/research/participants/portal/doc/call/h2020/jtics2-2017-cfp06-air-01-25/1762608-

cfp06_description_of_topics_en.pdf. [Accessed: 19-Jul-2019].

[74] D. Golovanov, M. Galea, and C. Gerada, "High specific torque motor for propulsion system of aircraft," 2016 Int. Conf. Electr. Syst. Aircraft, Railw. Sh. Propuls. Road Veh. Int. Transp. Electrif. Conf. ESARS-ITEC 2016.

[75] M. Galea, Z. Xu, C. Tighe, T. Hamiti, C. Gerada, and S. Pickering, "Development of an aircraft wheel actuator for green taxiing," 2014 Int. Conf. Electr. Mach., pp. 2492-2498, 2014.

[76] M. Galea, T. Hamiti, and C. Gerada, "Torque density improvements for high performance machines," 2013 Int. Electr. Mach. Drives Conf., pp. 1066-1073, 2013.

[77] A. Hebala, O. Hebala, W. A. M. Ghoneim, and H. A. Ashour, "Multiobjective particle swarm optimization of wind turbine directly connected PMSG," 2017 19th Int. Middle-East Power Syst. Conf. MEPCON, pp. 19-21, 2018.

[78] A. Hebala, W. A. M. Ghoneim, and H. A. Ashour, "Different design approaches of surface mounted high performance PMSG," in 2017 Intl Conf on Advanced Control Circuits Systems (ACCS) Systems \& 2017 Intl Conf on New Paradigms in Electronics Information Technology (PEIT), 2017, pp. 85-90.

[79] "An Airbus taxiing along with its engines shut down? It's not that far off!" [Online]. Available: https://www.safran-landingsystems.com/systems-equipment/electric-taxiing-0. [Accessed: 17Jul-2019].

[80] "Safran Eyes Launch Customer for 'E-Taxiing' at Farnborough." [Online]. Available: https://www.ainonline.com/aviationnews/defense/2018-07-17/safran-eyes-launch-customer-e-taxiingfarnborough. [Accessed: 17-Jul-2019].

[81] "IAI signs first $\$ 97 \mathrm{~m}$ TaxiBot deal." [Online]. Available: https://en.globes.co.il/en/article-1000767302. [Accessed: 17-Jul2019].

[82] I. Edem, O. Ikechukwu, I. A. E, and E. E. Ikpe, "The Future of Conventional Aircraft Ground Propulsion Systems in Relation to Fuel Consumption and CO 2 Emission," Int. J. Therm. Environ. Eng., vol. 
13, no. 2, pp. 91-100, 2016.

[83] D. Fordham et al., "Deriving Benefits from Alternative Aircraft-Taxi Systems," The National Academies Press, Washington, DC, 2016.

[84] S. Soepnel and P. C. Roling, "Impact of Electric Taxi Systems on Airport Apron Operations and Gate Congestion," in 17th AIAA Aviation Technology, Integration, and Operations Conference, 2017. P. C. Roling, P. Sillekens, R. Curran, and W. D. Wilder, "The effects of Electric Taxi Systems on airport surface congestion," 15th AIAA Aviat. Technol. Integr. Oper. Conf., no. June, pp. 1-10, 2015.

[86] N. Dzikus, R. Wollenheit, M. Schaefer, and V. Gollnick, "The Benefit of Innovative Taxi Concepts: The Impact of Airport Size, Fleet Mix and Traffic Growth," in 2013 Aviation Technology, Integration, and Operations Conference, 2013.

[87] "Remote towing: the future?" [Online]. Available: https://www.airsideint.com/issue-article/remote-towing-the-future/. [Accessed: 17-Jul-2019].

[88] "WheelTug plc to Provide Pilots 360 Degree View." [Online]. Available: https://www.globenewswire.com/newsrelease/2018/05/02/1494693/0/en/WheelTug-plc-to-Provide-Pilots360-Degree-View.html. [Accessed: 26-Sep-2019].

[89] "Autonomous Surface Operations: Operational Architectures and Paths to Deployment." [Online]. Available: https://nari.arc.nasa.gov/sites/default/files/attachments/12\%29 Robert Morris AutonomyWorkShop.pdf. [Accessed: 31-Jul-2019].

[90] A. Al-timimy, G. Vakil, M. Degano, P. Giangrande, C. Gerada, and M. Galea, "Considerations on the Effects that Core Material Machining has on an Electrical Machine 's Performance," IEEE Trans. Energy Convers., vol. 33, no. 3, pp. 1154-1163, 2018.

[91] A. Al-timimy, P. Giangrande, M. Degano, and M. Galea, "Design and Losses Analysis of a High Power Density Machine for Flooded Pump Applications," IEEE Trans. Ind. Appl., vol. 54, no. 4, pp. 3260-3270, 2018.

[92] F. Kelch, Y. Yang, B. Bilgin, and A. Emadi, "Investigation and design of an axial flux permanent magnet machine for a commercial midsize aircraft electric taxiing system," IET Electr. Syst. Transp., vol. 8, no. 1, pp. 52-60, 2018.

[93] C. Sciascera, P. Giangrande, L. Papini, C. Gerada, and M. Galea, "Analytical Thermal Model for Fast Stator Winding Temperature Prediction," IEEE Trans. Ind. Electron., vol. 64, no. 8, pp. 61166126, 2017.

[94] Z. Xu, C. Tighe, M. Galea, T. Hamiti, C. Gerada, and S. J. Pickering, "Thermal design of a permanent magnetic motor for direct drive wheel actuator," in 2014 International Conference on Electrical Machines, ICEM 2014, 2014, pp. 2186-2192.

[95] F. Zhang et al., "Back-iron Extension Thermal Benefits for Electrical Machines with Concentrated Windings," IEEE Trans. Ind. Electron., pp. 1-1, 2019.

[96] S. Wang et al., "Temperature Control of Permanent-Magnet Synchronous Motor Using Phase Change Material," 2015 IEEE Int. Conf. Adv. Intell. Mechatronics, pp. 1635-1640, 2015.

[97] S. Roggia, F. Cupertino, C. Gerada, and M. Galea, "A Two-Degreesof-Freedom System for Wheel Traction Applications," IEEE Trans. Ind. Electron., vol. 65, no. 6, pp. 4483-4491, 2018.

[98] S. Roggia, F. Cupertino, C. Gerada, and M. Galea, "Two-dimensional analysis for conical permanent magnet motors," 2018 XIII Int. Conf. Electr. Mach., pp. 1008-1014, 2018.

[99] S. Roggia, F. Cupertino, C. Gerada, and M. Galea, "Axial Position Estimation of Conical Shaped Motors for Aerospace Traction Applications," IEEE Trans. Ind. Appl., vol. 53, no. 6, pp. 5405-5414, 2017.

[100] S. Roggia, M. Galea, and C. Gerada, "Axial Position Estimation of Conical Shaped Motor for Green Taxiing Application," 2016 IEEE Energy Convers. Congr. Expo., pp. 1-6, 2016.

[101] F. Mendoza-Mondragón, V. M. Hernández-Guzmán, and J. Rodríguez-Reséndiz, "Robust Speed Control of Permanent Magnet Synchronous Motors Using," IEEE Trans. Ind. Electron., vol. 65, no. 8, pp. 6099-6108, 2018.

[102] L. Xie, J. Si, and Z. Wang, "Overview of 2-Degree-of-Freedom Rotary-Linear Motors Focusing on Coupling Effect," IEEE Trans. Magn., vol. 55, no. 4, pp. 1-11, 2019.

[103] O. Dobzhanskyi and R. Gouws, "Comparison Analysis of Electric Motors with Two Degrees of Mechanical Freedom : PM Synchronous Motor vs Induction Motor," 2016 II Int. Young Sci. Forum Appl. Phys. Eng., pp. 14-17, 2016.

[104] J. Wang, S. Huang, C. Guo, and Y. Feng, "Research on the Axial
Force of Conical-Rotor Permanent Magnet Synchronous Motors with Turbines," Energies, vol. 11, no. 10, 2018.

[105] J. Hoelzen et al., "Conceptual Design of Operation Strategies for Hybrid Electric Aircraft," Energies, pp. 1-26, 2018.

[106] C. E. Jones, P. J. Norman, S. J. Galloway, M. J. Armstrong, and M. Andrew, "Comparison of candidate architectures for future distributed propulsion aircraft," IEEE Trans. Appl. Supercond., vol. 26, no. 6, pp. 1-9, 2016.

[107] W. Xin and C. E. Lents, "A Study of Partial Discharge in High Voltage DC Distribution Systems for Hybrid Electric Aircraft," 2018 AIAA/IEEE Electr. Aircr. Technol. Symp., pp. 1-9, 2018.

[108] D. Zhang, J. He, D. Pan, M. Dame, and M. Schutten, "Development of Megawatt-Scale Medium-Voltage High Efficiency High Power Density Power Converters for Aircraft Hybrid-Electric Propulsion Systems Hardware Development of the Power Converter," 2018 AIAA/IEEE Electr. Aircr. Technol. Symp., pp. 1-5, 2018.

[109] A. El-refaie and M. Osama, "High Specific Power Electrical Machines: A System Perspective," in 2017 20th International Conference on Electrical Machines and Systems (ICEMS), 2017, pp. $1-6$.

[110] B. S. E. Schulz, "Exploring the High-Power Inverter," IEEE Electrif. Mag., vol. 5, no. March, pp. 28-35, 2017.

[111] D. Zhang, J. He, and D. Pan, "A Megawatt-Scale Medium-Voltage High Efficiency High Power Density “ SiC + Si ’ Hybrid Three-Level ANPC Inverter for Aircraft Hybrid- Electric Propulsion Systems," in 2018 IEEE Energy Conversion Congress and Exposition (ECCE), 2018, pp. 806-813.

[112] B. Sarlioglu and C. T. Morris, "More Electric Aircraft: Review, Challenges , and Opportunities for Commercial Transport Aircraft," IEEE Trans. Transp. Electrif., vol. 1, no. 1, pp. 54-64, 2015.

[113] Z. Huang, T. Yang, P. Giangrande, S. Chowdhury, M. Galea, and P. Wheeler, "An Active Modulation Scheme to Boost Voltage Utilization of the Dual Converter with a Floating Bridge," IEEE Trans. Ind. Electron., vol. 66, no. 7, pp. 5623-5633, 2019.

[114] X. Ding, Y. Zhou, and J. Cheng, "A Review of Gallium Nitride Power Device and Its Applications in Motor Drive," CES Trans. Electr. Mach. Syst., vol. 3, no. 1, pp. 54-64, 2019.

[115] B. Rahrovi and M. Ehsani, "A Review of the More Electric Aircraft Power Electronics," 2019 IEEE Texas Power Energy Conf., pp. 1-6.

[116] M. T. E. Heinrich, F. Kelch, P. Magne, and A. Emadi, "Investigation of regenerative braking on the energy consumption of an electric taxiing system for a single aisle midsize aircraft," IECON 2014 - 40th Annu. Conf. IEEE Ind. Electron. Soc., pp. 3023-3029, 2014.

[117] M. T. E. Heinrich, F. Kelch, P. Magne, and A. Emadi, "Regenerative Braking Capability Analysis of an Electric Taxiing System for a Single Aisle Midsize Aircraft," IEEE Trans. Transp. Electrif., vol. 1, no. 3, pp. 298-307, 2015.

[118] G. Z. Chen, "Supercapacitor and supercapattery as emerging electrochemical energy stores Supercapacitor and supercapattery as emerging electrochemical energy stores," Int. Mater. Rev., vol. 62, no. 4, pp. 173-202, 2017.

[119] K. M. Abraham, "Prospects and limits of energy storage in batteries," J. Phys. Chem. Lett., vol. 6, no. 5, pp. 830-844, 2015.

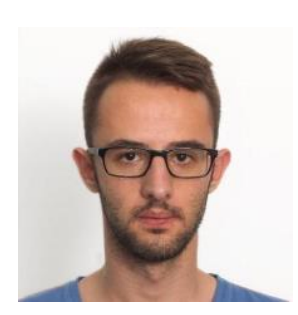

Milos Lukic received the BSc degree in Electrical Engineering from the University of Belgrade, Serbia in 2015. Between 2015 and 2017 he was a student of Erasmus Mundus Master Course in Sustainable Transportation and Electrical Power Systems (EMMC STEPS) jointly organised by University of Oviedo (ES), University of Nottingham (UK), University of Rome - Sapienza (IT), and the Polytechnic Institute of Coimbra (PT), from which he successfully obtained MSc degree in 2017. From October 2017, he is a Marie Curie Early Stage Research Fellow and a PhD candidate at the University of Nottingham. His current research interest includes areas related to electrified 
transportation such as modeling and control of electric drives, energy storage and energy management.

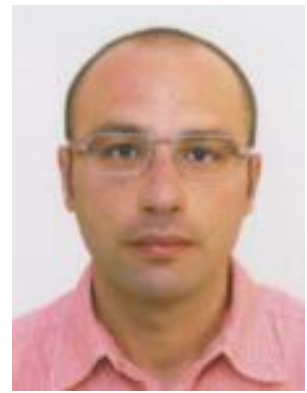

Paolo Giangrande received the Bachelor's (Hons.) and Master's (Hons.) degrees in electrical engineering at the Politecnico of Bari in 2005 and 2008, respectively. He received his $\mathrm{PhD}$ in electrical engineering at the Politecnico of Bari in 2011. Since 2012, he was Research Fellow at the University of Nottingham (UK), within the Power Electronics, Machines and Control Group. In 2018, he was appointed Senior Research Fellow and he is currently head of the Accelerated Lifetime Testing Laboratory at the Institute of Aerospace Technology, Nottingham. His main research interests include sensorless control of AC electric drives, design and testing of electromechanical actuators for aerospace, thermal management of high-performance electric drives and lifetime modelling of electrical machines.

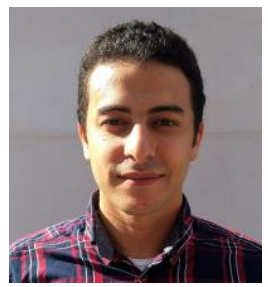

Ahmed Hebala received the BSc and MSc degrees in Electrical Engineering from the Arab Academy for Science, Technology and Maritime Transport, Alexandria, Egypt in 2013 and 2017 respectively, where he worked as an assistant lecturer for three years. Then he was appointed as a Marie Curie Early Stage Research Fellow and a PhD candidate at the University of Nottingham from January 2018. His main research interests include design and optimization electrical machine, thermal management of electrical machines, renewable energy sources and process automation.

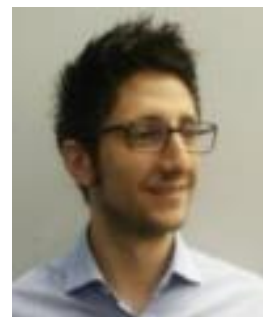

Stefano Nuzzo (M'18) received the B.Sc. and M.Sc. degrees in Electrical Engineering from the University of Pisa, Pisa, Italy, in 2011 and 2014, respectively. He received his Ph.D. degree in Electrical Engineering in 2018 from the University of Nottingham, Nottingham, U.K, where he is currently working as a Research Fellow within the Power Electronics, Machines and Control (PEMC) Group.

Since January 2019, he is also a Research Fellow at the Department of Engineering "Enzo Ferrari" at University of Modena and Reggio, Modena, Italy.

His research interests are the analysis, modelling and optimizations of electrical machines, with focus on salient-pole synchronous generators and brushless excitation systems for industrial power generation applications. He is also involved in a number of diverse projects related to the more electric aircraft initiative and associated fields.

Dr. Nuzzo is a Member of the IEEE Industrial Electronics Society (IES) and the IEEE Industry Applications Society (IAS). He constantly serves the scientific community as a reviewer for several journals and conferences.

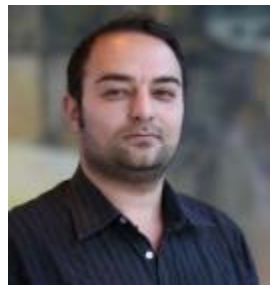

Michael Galea (M'13-SM'18, FRAeS) received the $\mathrm{Ph} . \mathrm{D}$. degree in electrical machines design in 2013 from the University of Nottingham, Nottingham, U.K. He was appointed as Lecturer in 2014, as Associate Professor in 2018 and as Professor in Electrical Machines and Drives in 2019, all with the University of Nottingham. He currently lectures in Electrical Machines and Drives and in Aerospace Systems Integration and manages a number of diverse projects and programmes related to the more/all electric aircraft, electrified propulsion, and associated fields. His main research interests include design and development of electrical machines and drives (classical and unconventional), reliability and lifetime degradation of electrical machines and the more electric aircraft. Michael is a Fellow of the Royal Aeronautical Society, a Senior Member of the IEEE and sits on the Executive Board of the UK Magnetics Society. Michael also serves an Associate Editor for the IEEE Transactions on Industrial Electronics and for the IET Electrical Systems in Transportation. 